\title{
VTT-006, an anti-mitotic compound, binds to the Ndc80 complex and suppresses cancer cell growth in vitro
}

Leena J. Laine ${ }^{1,2, *}$, Jenni H.E. Mäki-Jouppila1,2,3,4,*, Emma Kutvonen ${ }^{1,2}$, Pekka Tikkainen $^{1}$, Thomas K.M. Nyholm ${ }^{5}$, Jerry F. Tien ${ }^{6}$, Neil T. Umbreit ${ }^{6}$, Ville Härmä ${ }^{1}$, Lila Kallio ${ }^{1}$, Trisha N. Davis ${ }^{6}$, Charles L. Asbury ${ }^{7}$, Antti Poso ${ }^{8}$, Gary J. Gorbsky ${ }^{9}$ and Marko J. Kallio ${ }^{1,2}$

${ }^{1}$ VTT Health, VTT Technical Research Centre of Finland Ltd., Otaniemi, Finland

${ }^{2}$ Turku Bioscience Centre, University of Turku and Åbo Akademi University, Turku 20520, Finland

${ }^{3}$ Drug Research Doctoral Programme, University of Turku, Finland

${ }^{4}$ Department of Pharmacology, Drug Development and Therapeutics, University of Turku, Turku, Finland

${ }^{5}$ Department of Biosciences, Åbo Akademi University, Turku, Finland

${ }^{6}$ Department of Biochemistry, University of Washington, Seattle, WA, USA

${ }^{7}$ Department of Physiology and Biophysics, University of Washington, Seattle, WA, USA

${ }^{8}$ School of Pharmacy, University of Eastern Finland, Kuopio, Finland

${ }^{9}$ Cell Cycle and Cancer Biology Research Program, Oklahoma Medical Research Foundation, Oklahoma City, OK, USA

"These authors contributed equally to this work

Correspondence to: Marko J. Kallio, email: marko.kallio@fimea.fi

Keywords: $\mathrm{Hecl}$; Ndc80; mitosis; cell division; spindle assembly checkpoint

Received: July 07,2021 Accepted: December 01,2021 Published: December 10, 2021

Copyright: () 2021 Laine et al. This is an open access article distributed under the terms of the Creative Commons Attribution License (CC BY 3.0), which permits unrestricted use, distribution, and reproduction in any medium, provided the original author and source are credited.

\section{ABSTRACT}

Hec1 (Highly expressed in cancer 1 ) resides in the outer kinetochore where it works to facilitate proper kinetochore-microtubule interactions during mitosis. Hec1 is overexpressed in various cancers and its expression shows correlation with high tumour grade and poor patient prognosis. Chemical perturbation of Hec1 is anticipated to impair kinetochore-microtubule binding, activate the spindle assembly checkpoint (spindle checkpoint) and thereby suppress cell proliferation. In this study, we performed high-throughput screen to identify novel small molecules that target the Hec1 calponin homology domain (CHD), which is needed for normal microtubule attachments. 4 million compounds were first virtually fitted against the CHD, and the best hit molecules were evaluated in vitro. These approaches led to the identification of VTT-006, a 1,2-disubstituted-tetrahydro-beta-carboline derivative, which showed binding to recombinant Ndc80 complex and modulated Hec1 association with microtubules in vitro. VTT-006 treatment resulted in chromosome congression defects, reduced chromosome oscillations and induced loss of inter-kinetochore tension. Cells remained arrested in mitosis with an active spindle checkpoint for several hours before undergoing cell death. VTT-006 suppressed the growth of several cancer cell lines and enhanced the sensitivity of HeLa cells to Taxol. Our findings propose that VTT-006 is a potential anti-mitotic compound that disrupts M phase, impairs kinetochore-microtubule interactions, and activates the spindle checkpoint. 


\section{INTRODUCTION}

Highly expressed in cancer 1 (Hec1) is a conserved mitotic protein needed for faithful chromosome segregation and the maintenance of genomic balance $[1,2]$. Together with Nuf2, Spc24, and Spc25, Hec1 forms a dumbbell-shaped heterotetramer called the Ndc80 complex that stably locates to the outer kinetochore plate of chromosomes throughout mitosis [1-3]. In the complex, the globular domains and N-terminal tails of the Hec1Nuf2 dimer face outwards towards microtubules and the Spc24-Spc25 dimer orients towards the centromere [2]. The Ndc80 complex is a part of a large kinetochore signaling network termed KMN, which consists of the KNL-1 protein and the Mis12 protein complex [4]. The Ndc80 complex facilitates proper kinetochore-microtubule attachments $[1,5]$ and chromosome congression to the spindle equator [6], and recruits the spindle assembly checkpoint (the spindle checkpoint) proteins to the kinetochore $[7,8]$. During the establishment of correct kinetochore-microtubule interactions, the 80 amino acid long unstructured N-terminal tail of Hecl and the calponin homology domains (CHDs) of Hec1 and Nuf2 work in concert to control Ndc80 complex binding affinity to microtubules [9-13]. Binding is cooperative and predominantly electrostatic involving positive charges in the CHD and the N-terminal tail of Hec1 and negative charges in the $\mathrm{C}$-terminal tails of tubulin [11]. Aurora B phosphorylates the N-terminal tail of $\mathrm{Hec} 1$ at multiple sites and controls the establishment of correct kinetochore-microtubule attachments $[14,15]$ whereas Nek2 phosphorylates Ser165 in the $\mathrm{CH}$ domain and this way controls Hec1 mediated spindle checkpoint signalling and chromosome alignment process [16, 17]. Furthermore, Mps1 phosphorylation sites have been shown to control spindle checkpoint signalling [18].

Because of the important roles of the $\mathrm{Ndc} 80$ complex in mitosis and the overexpression of Hec1 in human tumors, targeting the complex may possess therapeutic value in the treatment of cancer. Ndc 80 depletion by RNAi has been shown to cause mitotic delay, persistent activation of the spindle checkpoint and subsequent cell death, and in nude mouse xenografts, suppression of tumor growth [7, 19, 20]. Similarly, amino acid mutations or deletions in Hecl domains involved in microtubule attachment impair the complex's ability to bind microtubules leading to mitotic errors [9]. Especially in the context of breast cancer, increased Hec1 expression has been suggested to play roles in both pre-neoplastic processes and late tumorigenesis. $\mathrm{Hec} 1$ is the most strongly upregulated gene in early breast tumorigenesis (i.e. the transition from normal breast tissue to benign breast tumors and ductal carcinoma in situ) and also showed marked upregulation, together with its regulators Aurora B kinases and Nek2, during breast tumor progression from invasive ductal grade I to grade III tumours [21]. A chemical inhibitor INH1 and its analogs have been reported to target $\mathrm{Hec} 1 / \mathrm{Nek} 2$ interaction leading to mitotic errors and apoptosis [22-24]. A previous study designed to identify small molecules that target the Hec1-microtubule interface identified SM15. However, this compound was found to hyperstabilize microtubules in the absence of Hec1, causing microtubule stabilization in both interphase and mitotic cells [25]. Here we report the discovery and characteristics of a novel anti-mitotic compound VTT-006, a 1,2-disubstituted-tetrahydro-betacarboline derivative, that interferes with Hec1-microtubule interaction in vitro and perturbs normal mitosis leading to growth suppression in cultured cancer cells.

\section{RESULTS}

\section{Identification of VTT-006 as a putative anti-Hec1 compound}

To identify small molecules that interfere with the binding of Hecl to microtubules, we first performed a virtual in silico high-throughput screen (HTS) using the FRED docking software [26]. About 4 million chemical structures obtained from large-diversity compound libraries of different vendors were virtually fitted against the CHD of Hec1 to determine their predicted binding performance. The crystallized structure of $\mathrm{Hec}_{81-196}$ [10] served as the docking template. After consensus scoring and visual inspection of the most potential docking poses, 138 compounds were purchased and tested in cell-based assays for their ability to induce cell cycle arrest at $\mathrm{M}$ phase and/or mitotic cell death, which are the reported outcomes of Hec1 loss-of-function by RNAi in cells [7]. The screen was conducted with live HeLa H2B-GFP cells that allowed the visualization of mitotic arrest based on DNA morphology. Three putative lead compounds, named VTT-006, VTT-102 and VTT-106, were identified to possess strong anti-mitotic properties (Figure 1A). Here we report the cellular phenotype and target protein binding properties of VTT-006, 2-(2-butynoyl)-1-(4-methoxy3-methylphenyl)-2,3,4,9-tetrahydro-1H-beta-carboline (Figure 1B). The compound docks into the CHD of $\mathrm{Hec} 1$ (Figure 1C) and is predicted to interact with $\mathrm{Hec} 1$ via hydrogen bonds between carbonyl oxygen of VTT006 and both Arg84 and Tyr160 on Hec1 (Figure 1D, Supplementary Figure 1).

\section{VTT-006 binds to the recombinant Ndc80 complex and affects its association with microtubules in vitro}

In order to validate the in silico predicted association of VTT-006 with the Ndc 80 complex in vitro, we used fluorescence anisotropy to determine the binding constant of VTT-006 to the Ndc80 complex. The recombinant Ndc80 complex (Bonsai), containing the globular 
domains required for microtubule binding and kinetochore localization, and a shortened rod domain [11], was used as the bait. Results showed that VTT-006 bound to Bonsai but not to negative control Aurora B (Figure 2A). The dissociation constant $\left(\mathrm{K}_{\mathrm{d}}\right)$ for VTT-006 was determined using a one site binding model that accounts for ligand depletion and was calculated to be $2.07 \pm 2.84 \mu \mathrm{M}$. Other hit compounds did not show clear binding to Bonsai using fluorescence anisotropy (results not shown) and were omitted from further studies.

Next, total internal reflection fluorescence microscopy (TIRF) was used to study whether VTT-006
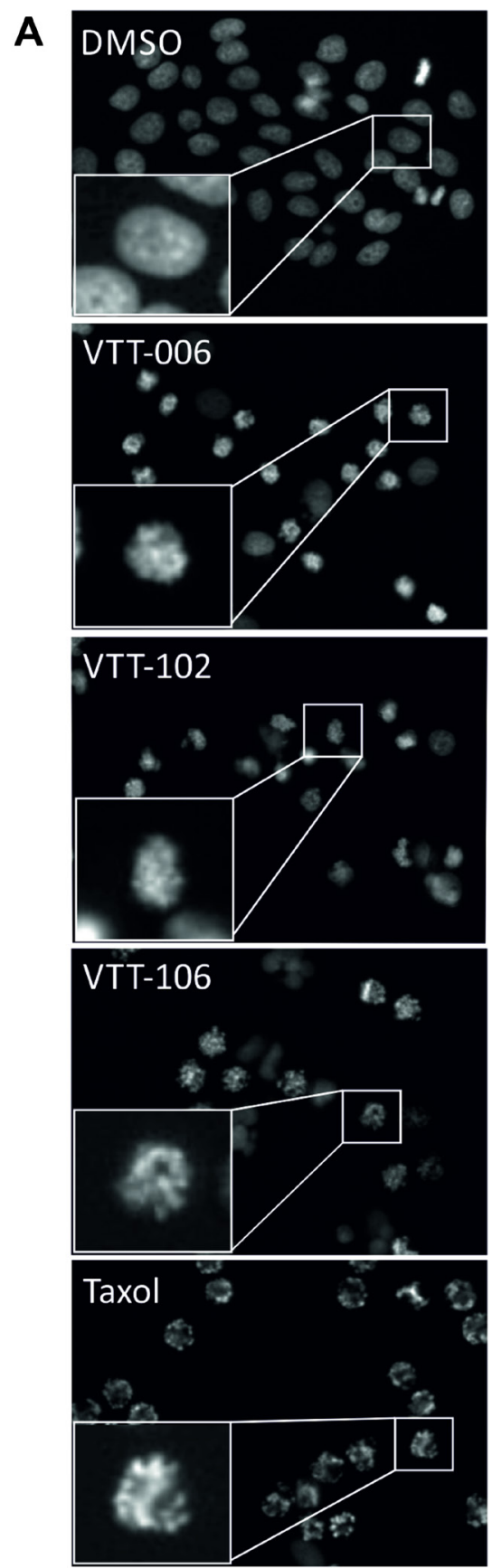

B
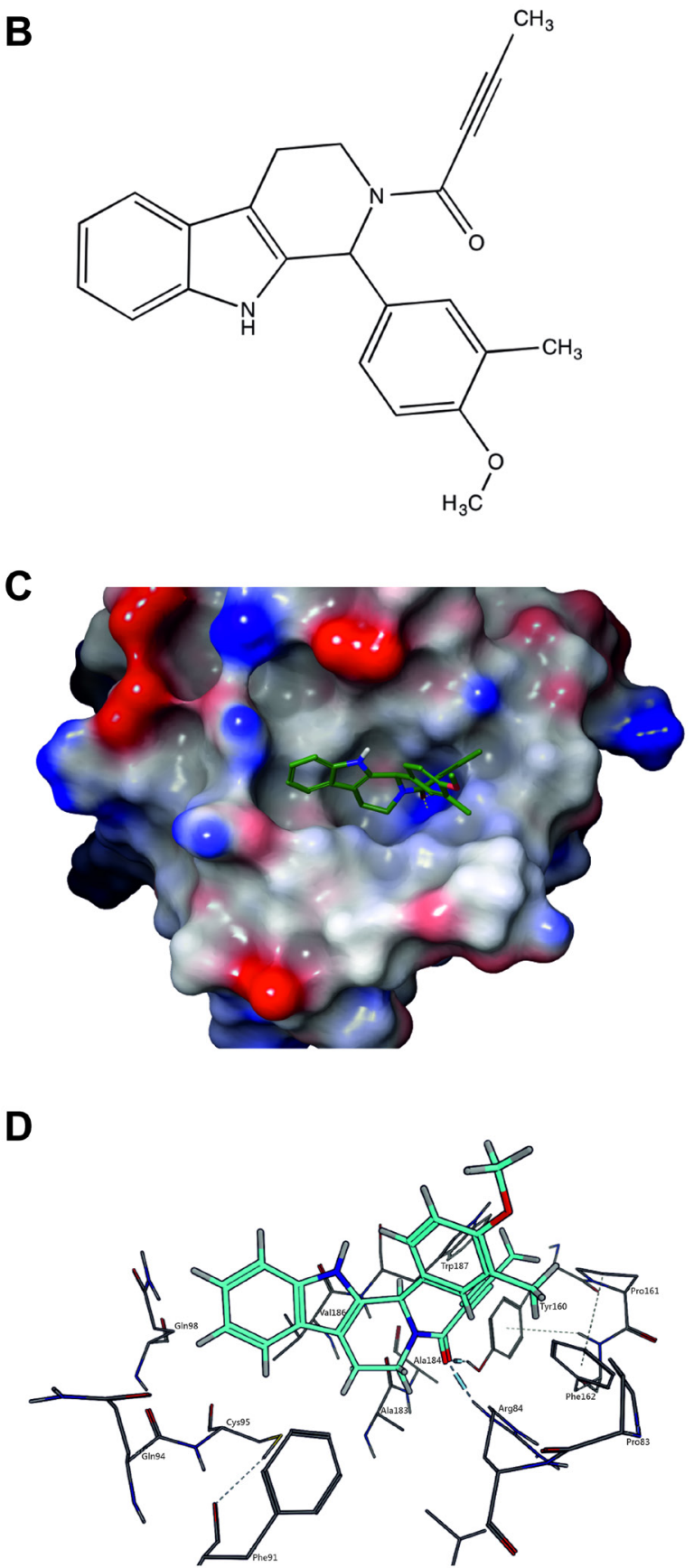

Figure 1: Identification of a novel LMW compound named VTT-006 from virtual and cell-based screens. (A) Images of representative wells from the cell-based screen showing mitotic accumulation by VTT-006, -102, -106 and control compound Taxol. HeLa cells stably expressing H2B-GFP were treated with $20 \mu \mathrm{M}$ concentration of experimental compounds or $600 \mathrm{nM}$ Taxol for $18 \mathrm{~h}$. Insets show magnified images of cells from the populations. (B) Structure of the hit compound VTT-006 is shown. (C) VTT-006 docked into the microtubule binding pocket of Hec1. Surface view of Hecl coloured by electrostatic potential is shown. Blue indicates positive charge and red negative charge. Nitrogens are coloured blue and oxygens red in the green stick model of VTT-006. Hydrogen bonds between carbonyl oxygen of VTT-006 and residues Arg84 and Tyr160 are indicated with dashed lines. (D) Close-up view illustrates VTT-006 (turquoise) and nearby amino acids of $\mathrm{Hec} 1$. 
affects the binding between the Ndc80 complex and Taxolstabilized microtubules in vitro. Analysis of the binding and diffusion of single Ndc80-GFP complexes on Taxolstabilized microtubules indicated that VTT-006 perturbed normal association of the complex with microtubules (Figure 2B-2D). The residence time of Ndc80-GFP on microtubules was significantly shorter in the presence of VTT-006 compared to DMSO (Figure 2B) indicating that the compound interferes with $\mathrm{Ndc} 80$-microtubule interaction. The off-rate constant increased from $0.47 \pm$ $0.02 \mathrm{~s}^{-1}$ to $0.79 \pm 0.04 \mathrm{~s}^{-1}(p<0.001)$. Furthermore, the diffusion constant increased slightly from $0.016 \pm 0.0005$ $\mu \mathrm{m}^{2} \mathrm{~s}^{-1}$ to $0.023 \pm 0.0006 \mu \mathrm{m}^{2} \mathrm{~s}^{-1}$ (Figure 2C). Together these results indicate that VTT-006 binds to the Ndc80 complex and affects its association with microtubules in vitro.

\section{VTT-006 induces mitotic arrest and cell death}

The mitotic effects of VTT-006 were first studied with HeLa cervical cancer cells that were time-lapse monitored using IncuCyte live-cell imager. The compound was applied at different concentrations on actively proliferating cell populations, which were followed for 48
A

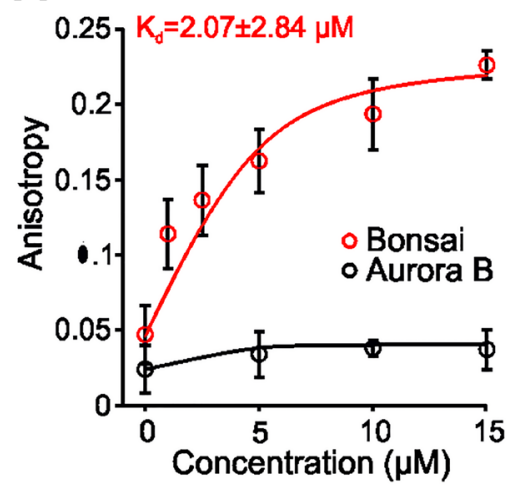

B

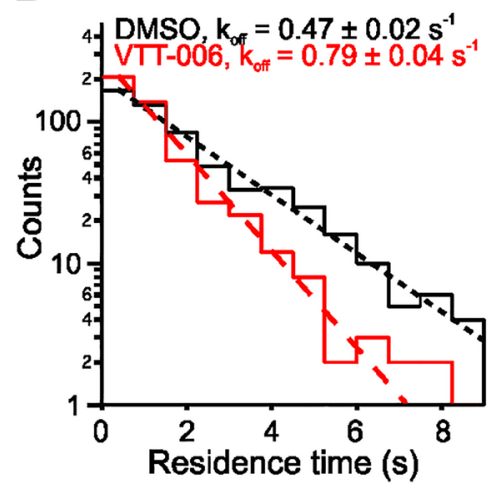

C

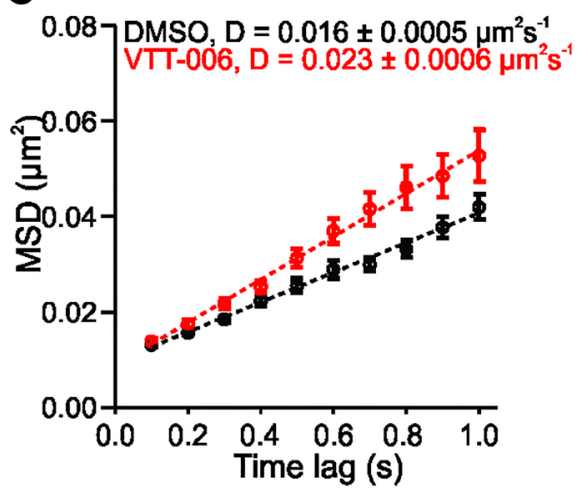

D
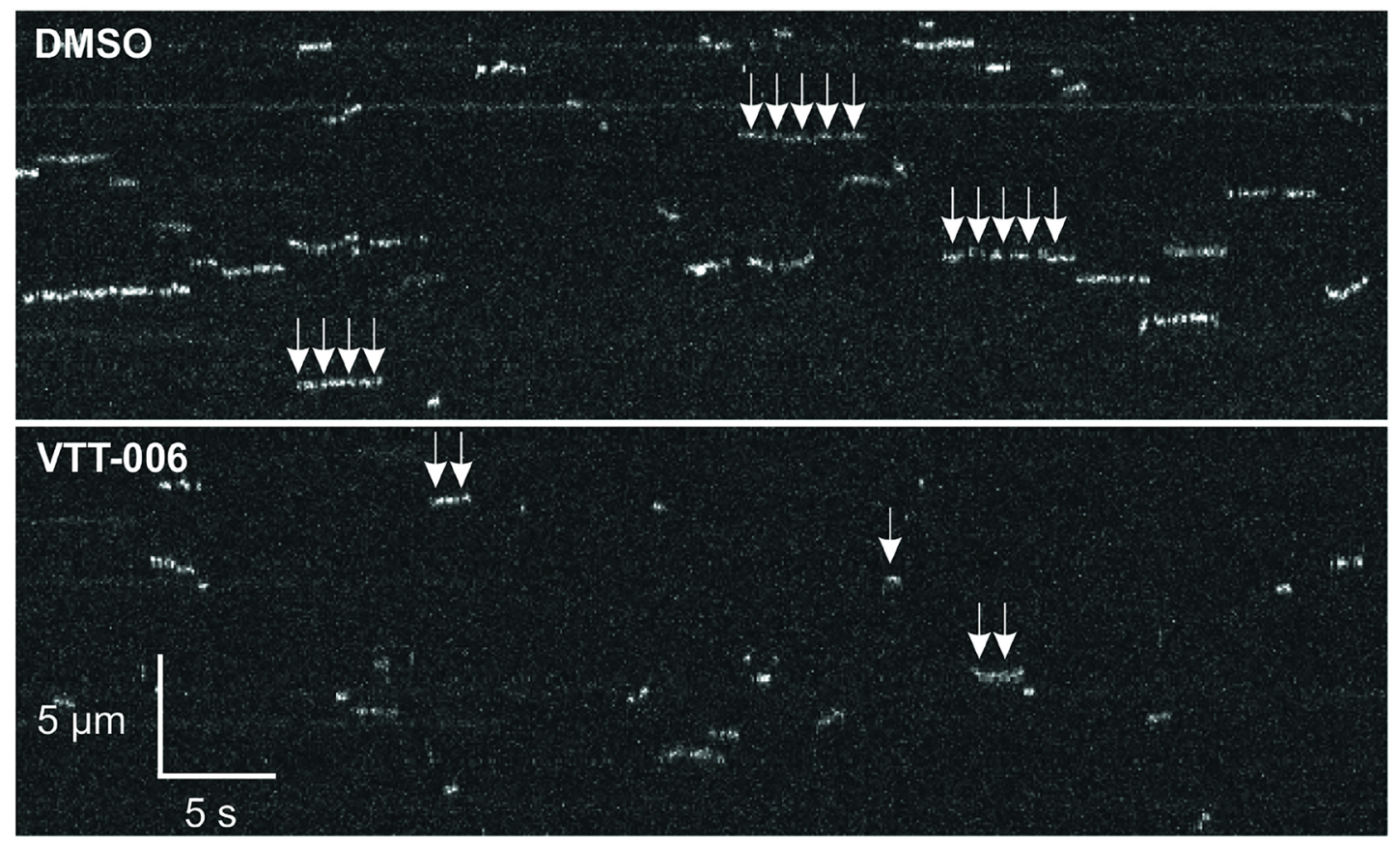

Figure 2: VTT-006 interacts with recombinant Ndc80 complex and reduces the residence time of Ndc80 complex on microtubules in vitro. (A) Fluorescence polarization assay showing VTT-006 binds to recombinant Ndc80 complex (Bonsai, $\mathrm{K}_{\mathrm{d}}=2.07$ $\pm 2.84 \mu \mathrm{M}$ ) but not to negative control protein Aurora B. VTT-006 was at $5 \mu \mathrm{M}$ and protein at $1-15 \mu \mathrm{M}$ concentration in solution. (B) Residence time distributions of Ndc80-GFP on microtubules fit with a single exponential (dashed line) to calculate the off-rate constant, $\mathrm{k}_{\text {off }}$ (C) Mean-squared displacement (MSD) $\pm \mathrm{SEM}$ versus time lag. A linear fit to the data (dashed line) was used to determine the diffusion constant, D. For (B) and (C), $n=581$ for DMSO control, $n=483$ for VTT-006. (D) Representative kymographs showing the binding and diffusion of single GFP-tagged Ndc80 complexes (depicted by arrows) on Taxol-stabilized microtubules. Ndc 80 complexes were assayed at $6-10 \mathrm{pM}$ in solution, in the absence or presence of $10 \mu \mathrm{M}$ VTT-006. Position along the microtubule is depicted on the vertical axis over time on the horizontal axis. 
$\mathrm{h}$ to determine mitotic and cell death indices. Typically, VTT-006 treated cells accumulated rapidly in mitosis and subsequently underwent cell death (Figure 3A). Cells treated with $5 \mu \mathrm{M}$ or $10 \mu \mathrm{M}$ VTT-006 showed significant mitotic accumulation at $6 \mathrm{~h}(18.0 \pm 3.0$ and $25.6 \pm 1.8 \%$, respectively) and maximal mitotic arrest occurred at 12 h $(36.1 \pm 4.7 \%$ for $5 \mu \mathrm{M}$ VTT-006 and $44.8 \pm 7.1 \%$ for $10 \mu \mathrm{M}$ VTT-006; Figure 3B). Mitotic arrest was followed by cell death culminating at $48 \mathrm{~h}(56.2 \pm 12.8 \%$ for $5 \mu \mathrm{M}$ and $96.0 \pm 2.7 \%$ for $10 \mu \mathrm{M}$ VTT-006; Figure 3C). We next analysed the duration of mitotic arrest and fates of individual cells from the IncuCyte films (Figure 3D). Treatment of cells with $10 \mu \mathrm{M}$ VTT-006 resulted in mitotic arrest that lasted on average $11.5 \pm 5.5 \mathrm{~h}(n=75$ cells) and was significantly longer compared to DMSO control $(1.2 \pm 0.3 \mathrm{~h}, n=75$ cells, $p \leq 0.001)$. The majority of the arrested cells appeared to die directly from mitosis ( $84.0 \%$ of cells), while the rest either divided to produce daughter cells $(8.0 \%)$ or exited $\mathrm{M}$ phase with failed cytokinesis $(8.0 \%)$. Taxol treated control cells died from mitosis (98.7\% of cells) after mitotic arrest had lasted on average $13.1 \pm 5.3 \mathrm{~h}$. Western blot analysis of cell extracts prepared from VTT-006 or Taxol treated HeLa cells showed that both compounds caused the appearance of cleaved PARP at $24 \mathrm{~h}$, confirming that the compounds induce apoptosis (Figure 3E).

Mitotic arrest is typically due to persistent spindle checkpoint activity in response to errors in spindle formation and/or kinetochore-microtubule attachments [27]. To find out the spindle checkpoint activity status in DMSO, VTT-006 or Taxol treated cells, we compared the levels of spindle checkpoint proteins, Bub1 and BubR1, at the kinetochores of HeLa cells using immunostaining. Kinetochore localization of these proteins marks active spindle checkpoint signalling [28, 29]. As expected, Bub1 and BubR1 kinetochore signals diminished markedly in DMSO treated control cells when mitosis proceeded from prometaphase to metaphase (Figure 3F, Supplementary Figure 2). In VTT-006 treated cells, Bub1 and BubR1 signals remained high at kinetochores of unaligned chromosomes (Figure 3F, Supplementary Figure 2) suggesting that VTT-006 induced mitotic arrest is spindle checkpoint mediated. We conclude that VTT006 triggers spindle checkpoint-dependent mitotic arrest that eventually leads to an increase in apoptotic signals.

\section{Impaired chromosome congression and oscillations in cells treated with VTT-006}

Mitotic progression was next analysed by high resolution live-cell imaging of HeLa H2B-GFP cells, which were followed for $15 \mathrm{~h}$ with 5 min interval after treatment with $5 \mu \mathrm{M}$ VTT-006. Live cell imaging results indicated that drug treatment caused defects in chromosome congression to the metaphase plate: several chromosomes remained unaligned near spindle poles while most chromosomes congressed to the metaphase plate (Figure 4A; Supplementary Movie 1). Defects in chromosome alignment persisted for several hours and cells remained arrested in mitosis until the end of the filming session, or they died directly from mitosis or soon after aberrant exit from mitosis (Supplementary Movie 1). In contrast to this, control cells divided with normal timing (Supplementary Movie 2).

Chromosome congression to the metaphase plate requires the establishment of lateral connections between kinetochores and microtubules in early mitosis allowing kinetochore sliding on microtubules, followed by the formation of stable end-on attachments, in which microtubules become embedded into the kinetochore [30, 31]. To study the effect of VTT-006 on lateral connections, we tracked kinetochores in live HeLa cells expressing GFP-Spc24 as a kinetochore marker. Cells were imaged at nuclear envelope breakdown (NEB) with $5 \mathrm{~s}$ interval and individual chromosomes/kinetochores exhibiting rapid movements were tracked to calculate the average speed of movement. Speeds slower than $10 \mu \mathrm{m} / \mathrm{min}$ were excluded from the measurements. In control cells, the average velocity of movement was $14.4 \pm 3.9 \mu \mathrm{m} / \mathrm{min}$ whereas in VTT-006 treated cells velocity was $13.9 \pm 3.3 \mu \mathrm{m} /$ min (Figure 4B). Thus, VTT-006 treatment did not affect rapid movements after NEB. Movements were similarly unaffected in cells treated with control drug Taxol at 20 $\mathrm{nM}$ concentration $(14.4 \pm 3.3 \mu \mathrm{m} / \mathrm{min})$. These results indicated that VTT-006 does not impair lateral connections and are consistent with earlier findings showing that the Ndc80 complex is not essential for lateral connections [32].

In contrast, the Ndc80 complex plays an essential role in the establishment of proper end-on attachments and is needed for oscillatory movements $[15,33]$. The mutations of certain residues in Hec1 and Nuf2 have been shown to influence inter-kinetochore tension reflecting the inability of the cells harbouring mutations to have normal kinetochore-microtubule attachments [9, 34]. We measured oscillations by tracking kinetochore pairs in cells stably expressing GFP-Spc24 and transiently transfected with GFP-NuMA for the visualization of poles. Cells were imaged at $5 \mathrm{~s}$ intervals after partial chromosome alignment at the metaphase plate and individual kinetochore pairs were tracked in chromosomes aligned at metaphase by time-lapse. Kinetochore movements were tracked in relation to one of the spindle poles. Kymographs in Figure 4C showing representative kinetochore pairs indicate that cells treated with $5 \mu \mathrm{M}$ VTT-006 or $20 \mathrm{nM}$ Taxol exhibited reduced oscillations in comparison to DMSO treated control cells. We quantified individual kinetochores to calculate deviation from average position, which is indicative of the amplitude of oscillation. Both VTT-006 and Taxol treatments significantly decreased deviation from average position in comparison to control (Figure 4D). Furthermore, VTT-006 treatment 
decreased inter-kinetochore distance (Figure 4E) whereas, interestingly, Taxol did not affect inter-kinetochore distance despite its effects on oscillation.

We next analysed whether reduced Hecl kinetochore levels could explain these observed phenotypes. According to immunofluorescent analysis, Hecl accumulated at kinetochores to similar levels in cells treated with VTT006 and in metaphase control cells indicating that the protein could accumulate normally at kinetochores in the presence of the drug (Supplementary Figure 3A and 3B). The Hec1 levels at kinetochores were lower in VTT-006 treated cells compared to the prometaphase control cells.
A
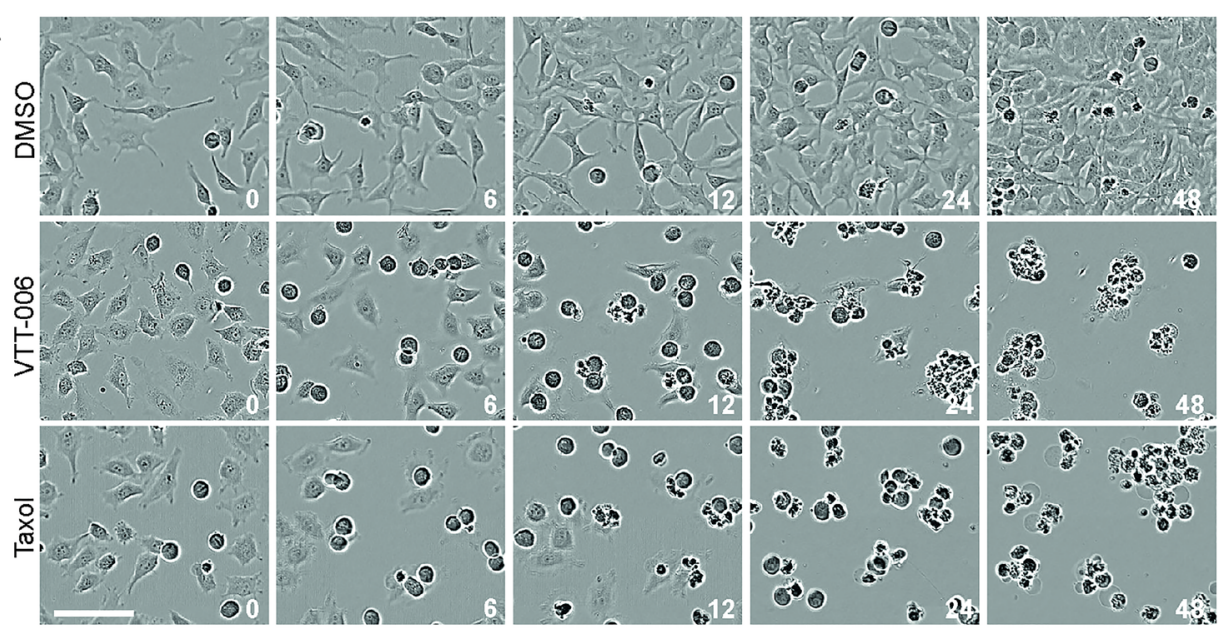

B

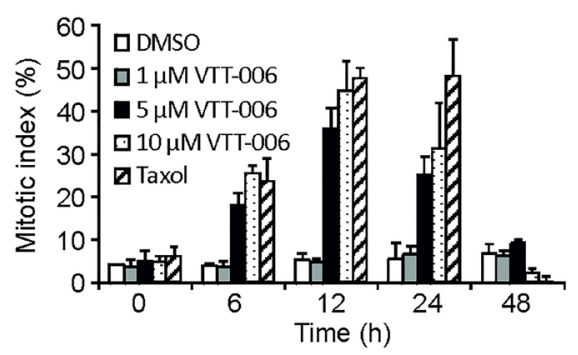

D
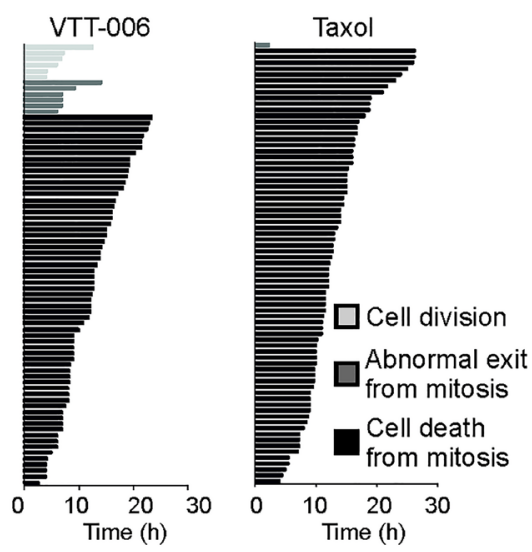

C

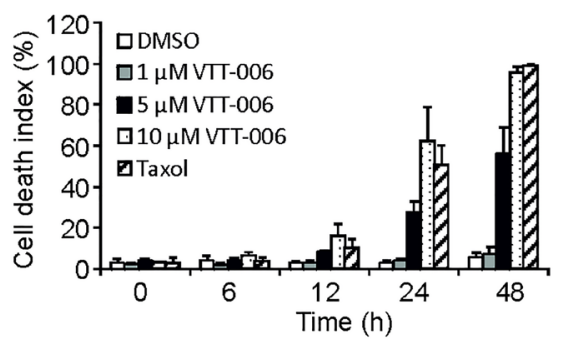

E

DMSO St Taxol VTT-006

$121224 \quad 1224 \mathrm{~h}$

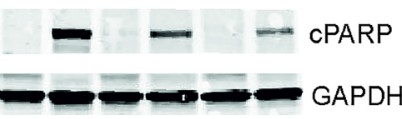

$\mathbf{F}$

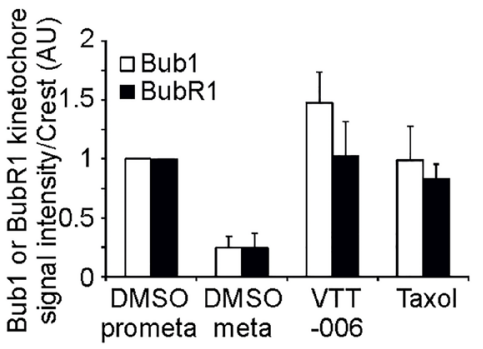

Figure 3: VTT-006 causes mitotic accumulation and apoptosis. (A) Representative images from IncuCyte films showing mitotic accumulation followed by cell death upon treatment with VTT-006 or Taxol. Time is indicated in h from the addition of the compounds. $(B, C)$ Quantification of mitotic (B) and cell death (C) indices from IncuCyte films of cells with indicated compounds and concentrations. Result is average \pm SD from 3 replicate experiments. One well ( $n \geq 150$ cells) was analysed in each experiment. (D) Analysis of mitotic phenotype and the length of mitosis from IncuCyte films. 75 cells were analysed ( 25 from each experiment). (E) Western blot showing VTT006 induces PARP cleavage (cPARP) after $24 \mathrm{~h}$ treatment. Staurosporine (St) at $1 \mu \mathrm{M}$ was used as a positive control. (F) Quantification of Bub1 and BubR1 kinetochore signals. For VTT-006, only unaligned chromosomes near spindle poles were quantified. Result is average \pm SD from 3 replicate experiments (8-15 cells and 20 kinetochores per cell were quantified in each experiment). For (A), (D), (E) and (F) HeLa cells were treated with $10 \mu \mathrm{M}$ VTT-006 or $100 \mathrm{nM}$ Taxol. Scale bar $=100 \mu \mathrm{m}$. 
A
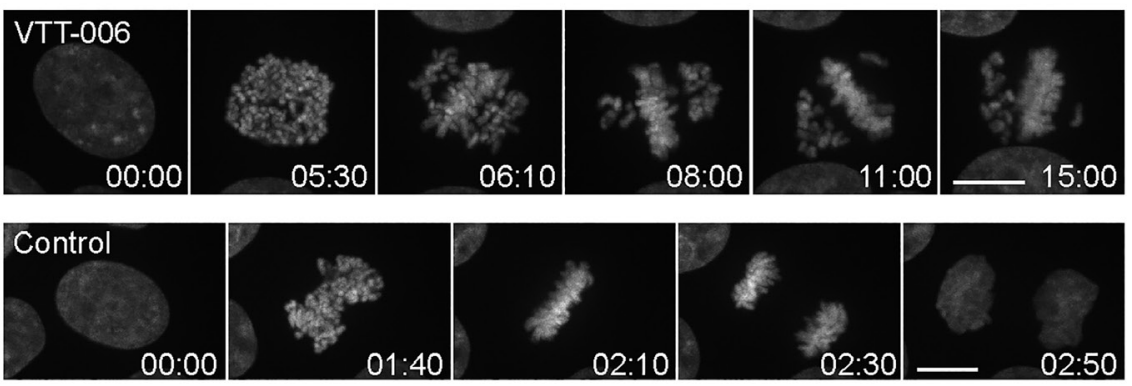

B

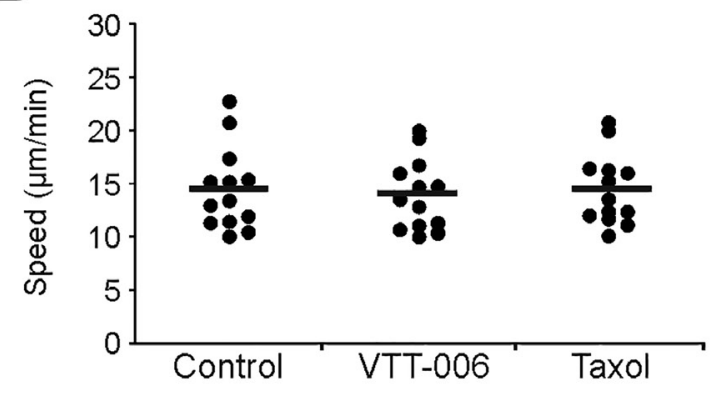

D

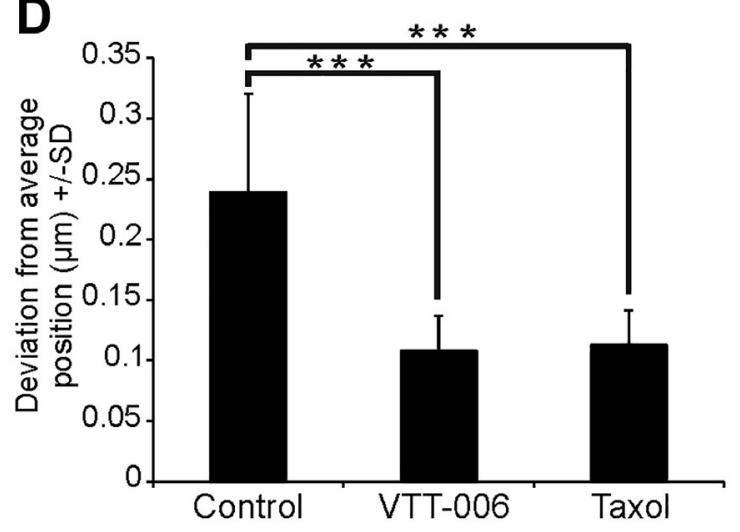

E

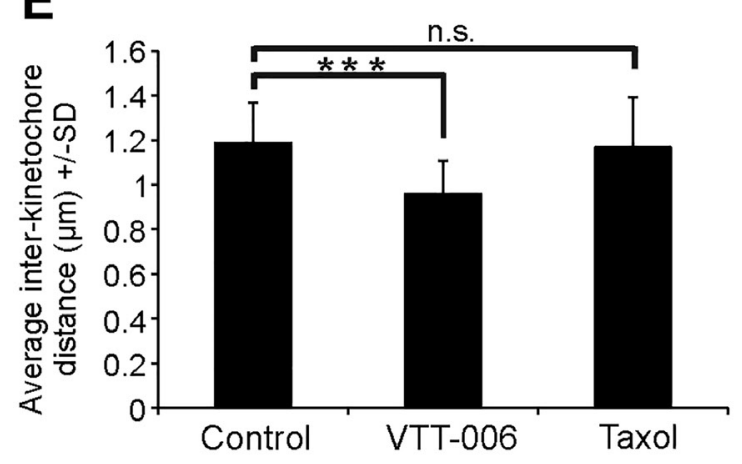

C
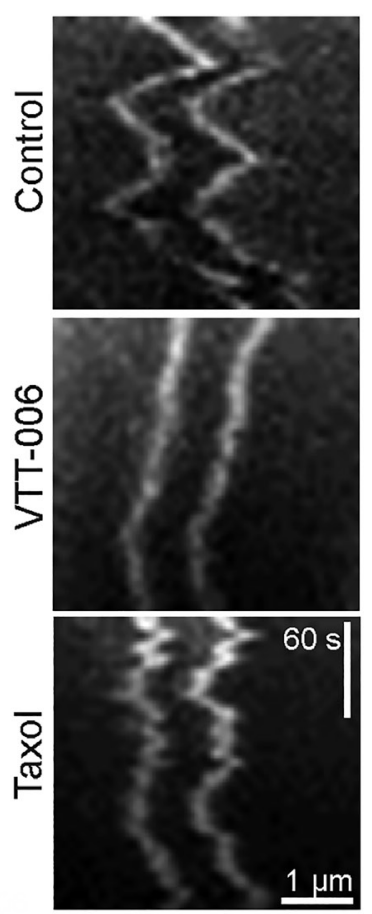

Figure 4: VTT-006 treatment results in chromosome congression defects and dampened kinetochore oscillations at the metaphase plate. (A) Still images from time-lapse films of a representative HeLa H2B-GFP cell treated with $5 \mu$ M VTT-006, and an untreated control. Time is shown in hours and minutes. (B) Graph showing the effect of VTT-006 on rapid ( $\geq 10 \mu \mathrm{m} / \mathrm{min}$ ) chromosome movements in early mitotic cells. Cells were imaged at NEB with $5 \mathrm{~s}$ interval and individual chromosomes/kinetochores were tracked to calculate the average speed of movement. $N=13$ kinetochores from 6-7 cells. (C) Kymographs from representative GFP-Spc24 HeLa cells showing metaphase kinetochore oscillations. (D) Graph showing deviation from average kinetochore position \pm SD. (E) Inter-kinetochore distance in mitotic GFP-Spc24 HeLa cells. Result is average from 85 kinetochore pairs \pm SD. (B-E) GFP-Spc24 Hela cells were used to track kinetochores in cells treated with DMSO, $5 \mu \mathrm{M}$ VTT-006 or $20 \mathrm{nM} \mathrm{Tx}$ for $1-3 \mathrm{~h}$. Data were obtained from sister kinetochores that were in the same focal plane. 
In whole cell lysates, the total Hecl protein quantities were similar in cells treated with VTT-006, vehicle, Taxol or nocodazole (Supplementary Figure 3C). We also assessed whether kinetochores in VTT-006 treated cells could establish cold-stable attachments with microtubules by lysing Hela cells in cold calcium buffer to deplete non-kinetochore microtubules. After treatment of cells with VTT-006, visible microtubule bundles extended towards chromosomes at the metaphase plate as well as near the spindle poles, which suggests existence of stable kinetochore-microtubule attachments (Supplementary Figure 4). Therefore, the inability of some chromosomes to congress was not likely due to the absence of kinetochoremicrotubule connections. Furthermore, we tested the effects of VTT-006 on tubulin polymerization in vitro. The results demonstrate that VTT-006 slightly stabilizes tubulin polymerization with high $20 \mu \mathrm{M}$ concentration (data not shown), which can contribute to the observed cellular phenotypes.

To test whether VTT-006 affects chromosomes that have aligned at the spindle equator (i.e., have established correct kinetochore-microtubule attachments), we took advantage of the proteasome inhibitor MG132, which prevents cells from exiting $M$ phase in a spindle checkpoint -dependent manner while allowing normal chromosome congression to the metaphase plate [35]. Cells were pre-treated with MG132 for $2 \mathrm{~h}$ to accumulate metaphase cells, and then the culture medium was supplemented with $10 \mu \mathrm{M}$ VTT-006 or $20 \mathrm{nM}$ Taxol followed by live-cell imaging. As expected, in MG132 treated cells all chromosomes remained in a metaphase configuration for the whole duration of the filming session (Supplementary Movie 3). In contrast, many chromosomes left the metaphase plate in cells treated with VTT-006 and moved close to one of the spindle poles (Supplementary Movie 4) whereas in cells treated with Taxol a more severe disruption of the metaphase plate was observed (Supplementary Movie 5). Therefore, in addition to inhibitory effects on chromosome alignment in early mitosis, VTT-006 also disrupts normal attachments of chromosomes that have already aligned at the metaphase plate.

\section{VTT-006 effect on chromosome alignment is reversible}

To further quantify the cellular phenotype after treatment with VTT-006 and to assess whether the anti-mitotic effect of the drug is reversible, HeLa cells were treated with DMSO, $10 \mu \mathrm{M}$ VTT-006 or $100 \mu \mathrm{M}$ monastrol for $5 \mathrm{~h}$, and processed for immunostainings to detect microtubules, spindle poles and DNA, or alternatively the drugs were washed off and cells were cultured in the presence of MG132 for $1.5 \mathrm{~h}$ before fixation and immunostaining. We hypothesized that unless the VTT-006 impact is irreversible, normal chromosome congression to the metaphase plate should ensue upon drug washout and incubation in the presence of MG132. Before washout, analysis showed that VTT-006 treatment resulted in bipolar cells with partial chromosome alignment (58.0 $\pm 4.1)$, multipolar cells $(25.8 \pm 7.2 \%)$, bipolar cells with no chromosome alignment $(8.4 \pm 3.0 \%)$, bipolar cells with complete metaphase alignment $(1.3 \pm 0.6 \%)$ and monopolar cells $(6.5 \pm 5.1 \%)$ (Figure $5 \mathrm{~A}$ and $5 \mathrm{~B})$. In sharp contrast to this, after VTT-006 washout, $75.3 \pm 5.8 \%$ of cells displayed complete metaphase alignment after 1.5 $h$ recovery in the presence of MG132 (Figure 5A and 5B). This metaphase alignment was similar to that seen after monastrol washout into MG132 (73.7 \pm 7.9) (Figure $5 \mathrm{~B})$. In DMSO treated cell populations, the proportion of complete metaphases was $82.0 \pm 1.2 \%$ after washout (Figure 5B). These results indicate that VTT-006's inhibitory effect on chromosome alignment is reversible.

\section{VTT-006 treatment increases the recruitment of Aurora B kinase at kinetochores}

Aurora B kinase has been reported to control Hec1 by modulating its affinity to microtubules [4, 11, 12]. Moreover, the kinase is also required for correction of erroneous kinetochore-microtubule attachments during early mitosis [36]. For these reasons we examined if VTT-006 causes changes in Aurora B localization and activity. Cells were treated with DMSO, VTT-006, Taxol or nocodazole for $6 \mathrm{~h}$, or a combination of Aurora inhibitor ZM447439 and MG132 for $2 \mathrm{~h}$. MG132 was used to block mitotic exit induced by Aurora kinase inhibitor [37]. After treatments, cells were fixed and immunostained with antibodies against Aurora B, p-Aurora B (Thr232) and Crest. Autophosphorylation of Aurora B on Thr232 was measured to detect the active state of the kinase [38]. Analysis revealed a significant accumulation of Aurora $\mathrm{B}$ at the centromeres of unaligned chromosomes in cells treated with VTT-006. Indeed, the amount of the kinase was increased by 2.5 -fold in comparison to DMSO controls (Supplementary Figure 5, $p \leq 0.05$ ). Moreover, line-scan analysis of the signal distribution across the centromere-kinetochore pairs indicated that Aurora B labelling spread out towards the kinetochores at unaligned chromosomes whereas in control cells Aurora B localized sharply to the inner centromere region (Supplementary Figure 6). The activity of the kinase at unaligned chromosomes was at the level of control prometaphase cells (Supplementary Figure 5). These results indicate that Aurora B accumulates at higher levels at centromeres/ kinetochores of unaligned chromosomes in VTT-006 treated cells.

\section{VTT-006 sensitizes HeLa cells to Taxol}

Hec1 depletion by RNAi has earlier been shown to cause sensitization to Taxol treatment [39]. To examine 
possible synergistic effects between VTT-006 and Taxol, we treated HeLa cells with varying concentrations of the two drugs either as single dosages or as drug combinations, and monitored the viability of cells with the IncuCyte imager. Combinations of low concentrations of VTT-006 (1-2 $\mu \mathrm{M})$ and Taxol (1-5 nM) increased mitotic index in comparison to single drug treatments at the same concentrations (Figure 6A). In some cases, the increases in mitotic index of the combinations appeared to be synergistic rather than simply additive. Cells treated with a combination of $2 \mu \mathrm{M}$ VTT-006 and $5 \mathrm{nM}$ Taxol exhibited clearly increased cell death 24-48 h after administration of the drug cocktail (Figure 6B) in comparison to cell populations treated with $2 \mu \mathrm{M}$ VTT-006 or $5 \mathrm{nM}$ Taxol as single treatments. Cell death coincided with the induction of cleaved PARP indicating apoptotic cell death (Figure $6 \mathrm{C})$. Based on these findings, sub-lethal doses of VTT-006 sensitize cells to low nanomolar concentrations of Taxol.

\section{VTT-006 inhibits the growth of various cancer cell lines}

In addition to HeLa cells, the effects of VTT-006 on cell viability were studied on a panel of cell lines

\section{A}

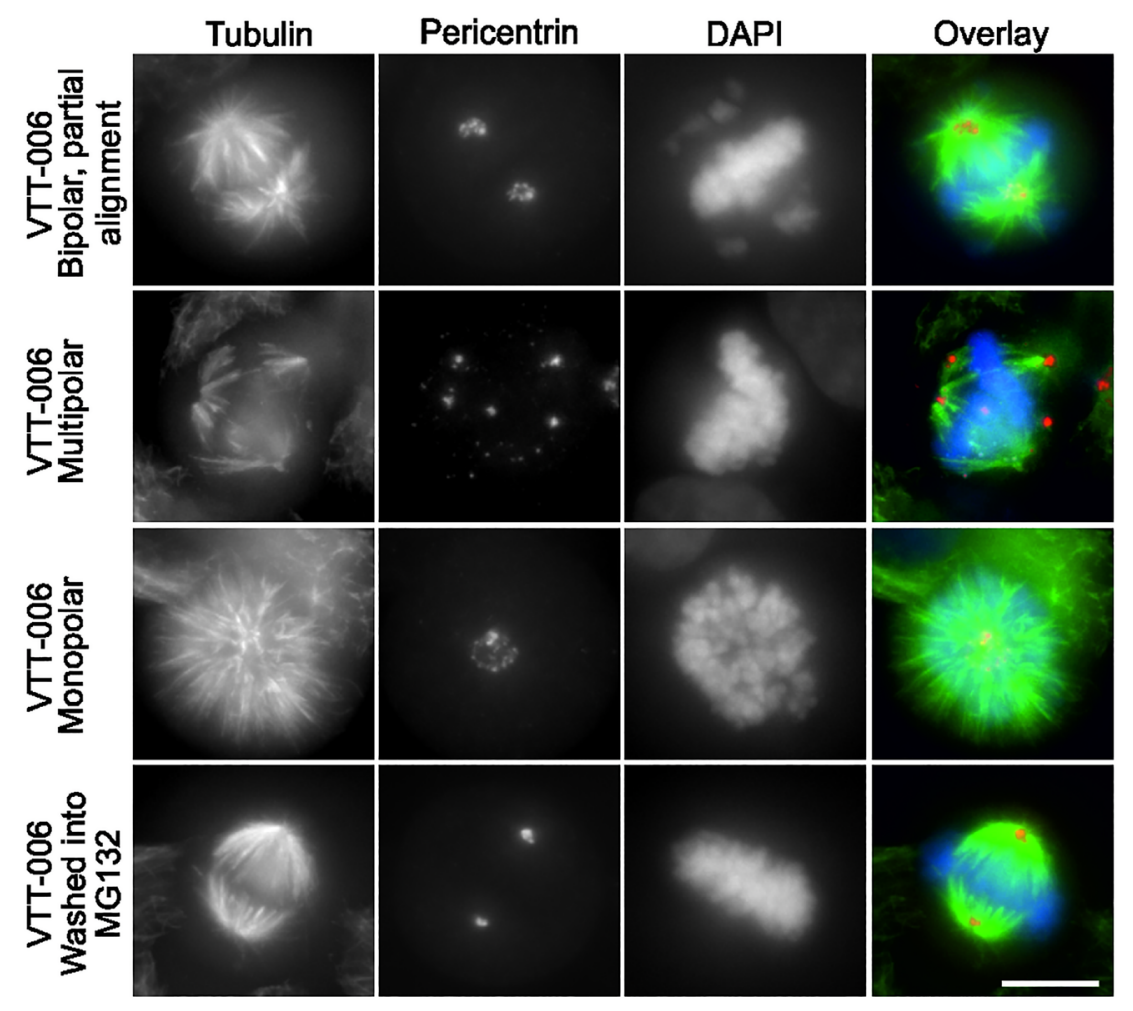

B

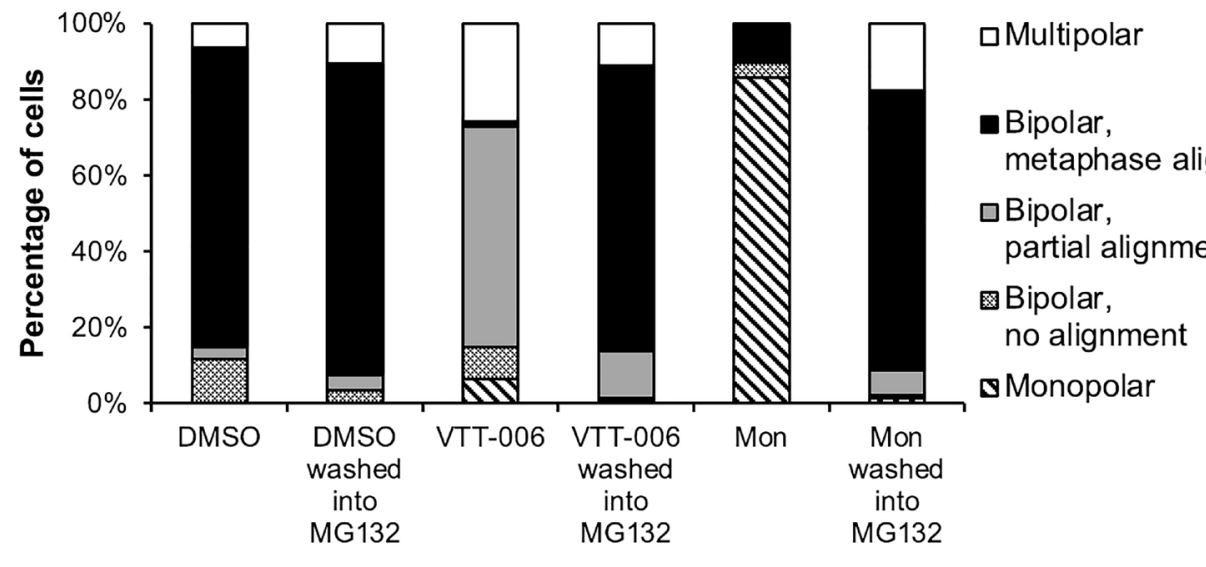

Figure 5: VTT-006 causes reversible chromosome misalignment. (A) Images of VTT-006 treated cells displaying chromosome alignment and spindle defects, and a metaphase cell with proper chromosome alignment after drug washout (bottom row). (B) Quantification of the phenotype from the drug washout experiment. HeLa cells were treated with DMSO, $10 \mu \mathrm{M}$ VTT-006 or $100 \mu \mathrm{M}$ monastrol for $5 \mathrm{~h}$ followed by wash into medium containing MG132 for $1.5 \mathrm{~h}$. Result is average from 3 replicate experiments. 100 cells were analyzed in each experiment. Scale bar $=10 \mu \mathrm{m}$. 
including cancer cells derived from breast, prostate, colon, lung and ovarian tissues and three non-malignant cell lines using CellTiter Glo assays. $\mathrm{EC}_{50}$ values were in the range of 4.8-11.9 $\mu \mathrm{M}$ for other cell lines except for MCF10A, which had an $\mathrm{EC}_{50}$ value of $21.3 \mu \mathrm{M}$ indicating that this non-tumorigenic breast cell line is more resistant to VTT-006 (Table 1). However, the viability of nontumorigenic prostate cell lines Ep156T and RWPE-1 was decreased by VTT-006. The same cell lines observed with the IncuCyte imager also showed accumulation in mitosis when treated with 1,5 or $10 \mu \mathrm{M}$ VTT-006 with the exception of MCF10A cells, which did not undergo mitotic arrest (results not shown). Finally, growth suppressive effects of VTT-006 were studied in 3D organotypic cell culture system [40] using breast cancer cell lines MCF7 and MDA-MB-231 SA as models. The growth of the multicellular spheroids was efficiently retarded by $5 \mu \mathrm{M}$ and higher concentrations of VTT-006 determined by morphometric spheroid criteria (Figure 7). The results indicate similar efficacy for VTT-006 in monolayer and 3D cell culture models.

\section{DISCUSSION}

We describe here the cellular effects and antiproliferative activities of VTT-006, a small molecule that binds to Hecl and perturbs its association with microtubules in vitro. To our knowledge, no previous studies have reported small molecules that would directly inhibit Hec1 function. One set of developmental compounds originating from the INH1 template has been shown to impair Hec1-Nek2 kinase interaction leading to the degradation of the kinase and growth suppression in multiple human cancer cell lines in culture and in mouse xenografts $[22,24]$. In addition, the molecule SM15 has been reported to bind the surface of microtubules independently from $\mathrm{Hec} 1$ and to stabilize microtubules and the microtubule-kinetochore interaction [25]. Future comparative studies with these three compounds could further help to determine their different effects on cell proliferation at molecular level. We aimed at the discovery of compounds that would prevent the establishment of proper microtubule-kinetochore interactions via targeting the CHD of Hec1. Perturbation of the dynamic instability of microtubules by filament-destabilizing agents such as vinblastine and vincristine, or by filament-stabilizing drugs paclitaxel, docetaxel and epothilones has been utilised for decades to treat cancer patients [41]. Due to poor cancer cell selectivity of microtubule-targeting drugs and their side effects, such as peripheral neuropathy, new anti-mitotic compounds have been actively developed against e.g., mitotic motor proteins Eg5 and Cenp-E [42, 43], Plk1 and Aurora kinases [44-47], and other key facilitators of cell division [48, 49]. However, the majority of non-microtubule targeting anti-mitotics have not translated their preclinical efficacy to a tolerable clinical response, which has fueled early drug discovery and new target validation studies in the field of mitosis research.

$\mathrm{Hec} 1$ is an interesting drug target protein for many reasons. Its normal function is indispensable for ordered chromosome segregation and cell cycle progression [1, 2]. Depletion of the protein by siRNA or virus-mediated RNAi has been shown to suppress cancer cell growth in cells and xenograft models $[19,20]$. On the other hand, the oncogenic properties of Hec1 were demonstrated in a transgenic mouse model where protein overexpression was associated with elevated frequency of tumour formation [50]. Importantly, to date $\mathrm{Hec} 1$ has not been reported to possess any functions outside mitosis that in principle limits the effects of a Hecl inhibitor to actively proliferating cell types. Therefore, hypothetically, by interfering with microtubule-kinetochore associations using a Hecl drug one can avoid the obstruction of microtubule dynamics in non-dividing cells such as neurons and thereby reduce clinical adverse effects in comparison to spindle poisons. These notions together with the well-established Hecl overexpression found in a wide range of human tumours emphasize the clinical potency of $\mathrm{Hecl}$ inhibition.

Anisotropy measurements indicated clear binding, albeit at low micromolar affinity, for VTT-006 to recombinant Ndc80 complex. This ranks the compound into the group of so-called general-affinity ligands that typically exhibit $\mathrm{K}_{\mathrm{d}}$ values in the range of $10^{-4}$ to $10^{-6} \mathrm{M}$ and may bind to more than one protein [51]. Therefore, we cannot exclude the possibility that VTT-006 would target other proteins besides $\mathrm{Hec} 1 / \mathrm{Ndc} 80$ complex. The binding data proposes an intermediate affinity for VTT-006 on Hec1, which may enable compound to switch between bound and non-bound states with its ligand(s).

Our results with VTT-006 from in vitro and cellbased assays are consistent with a partial inhibition of Hec1/Ndc80 function. TIRF microscopy revealed that the compound significantly shortened the residence time of Ndc80-GFP on Taxol-stabilized microtubules but did not fully abolish the complex's ability to bind to the filaments. This effect resembled the outcome of mutating Aurora B target residues in the N-terminal tail or complete loss of the tail region, both of which reduce the residence time of Ncd80 complex on microtubules in TIRF assays [52]. Partial inhibition is also consistent with the observation that the spindle checkpoint is active in the presence of VTT-006 as complete depletion of $\mathrm{Ndc80}$ has been reported to abrogate the spindle checkpoint $[6,53]$. Moreover, our results indicate that Aurora B accumulates at higher levels at kinetochores of unaligned chromosomes in VTT-006 treated cells, which could be related to amplification of the spindle checkpoint signal to maintain mitotic arrest, or to error correction via increased phosphorylation of $\mathrm{Hec} 1$ or other substrates at the centromeres and kinetochores of unaligned chromosomes [54]. 
Our data indicate that the compound has an ability to modulate the $\mathrm{Ndc} 80$-microtubule interaction in vitro. Live cell imaging and immunofluorescence assays showed that VTT-006 treated cells exhibited partial chromosome misalignment with cold stable kinetochore-microtubule attachments and reduced inter-kinetochore tension. These results are consistent with the study by Tooley et al. reporting chromosome misalignment, reduced

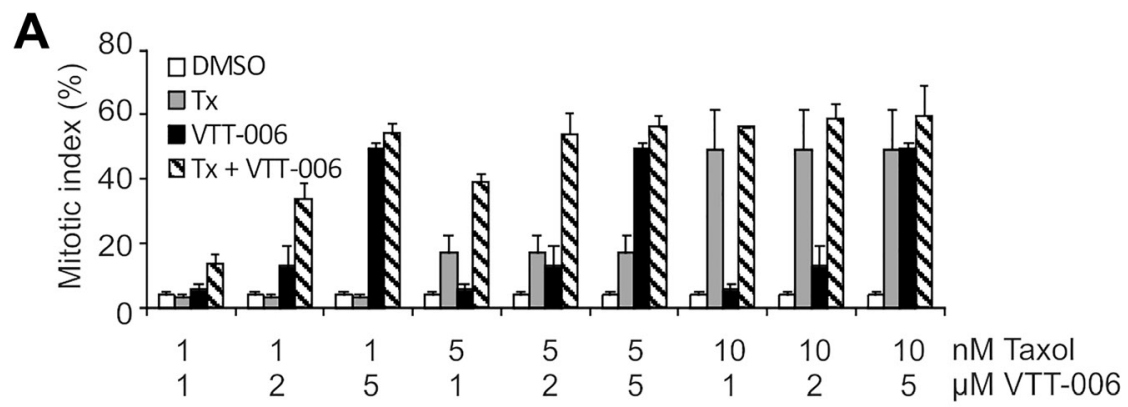

B
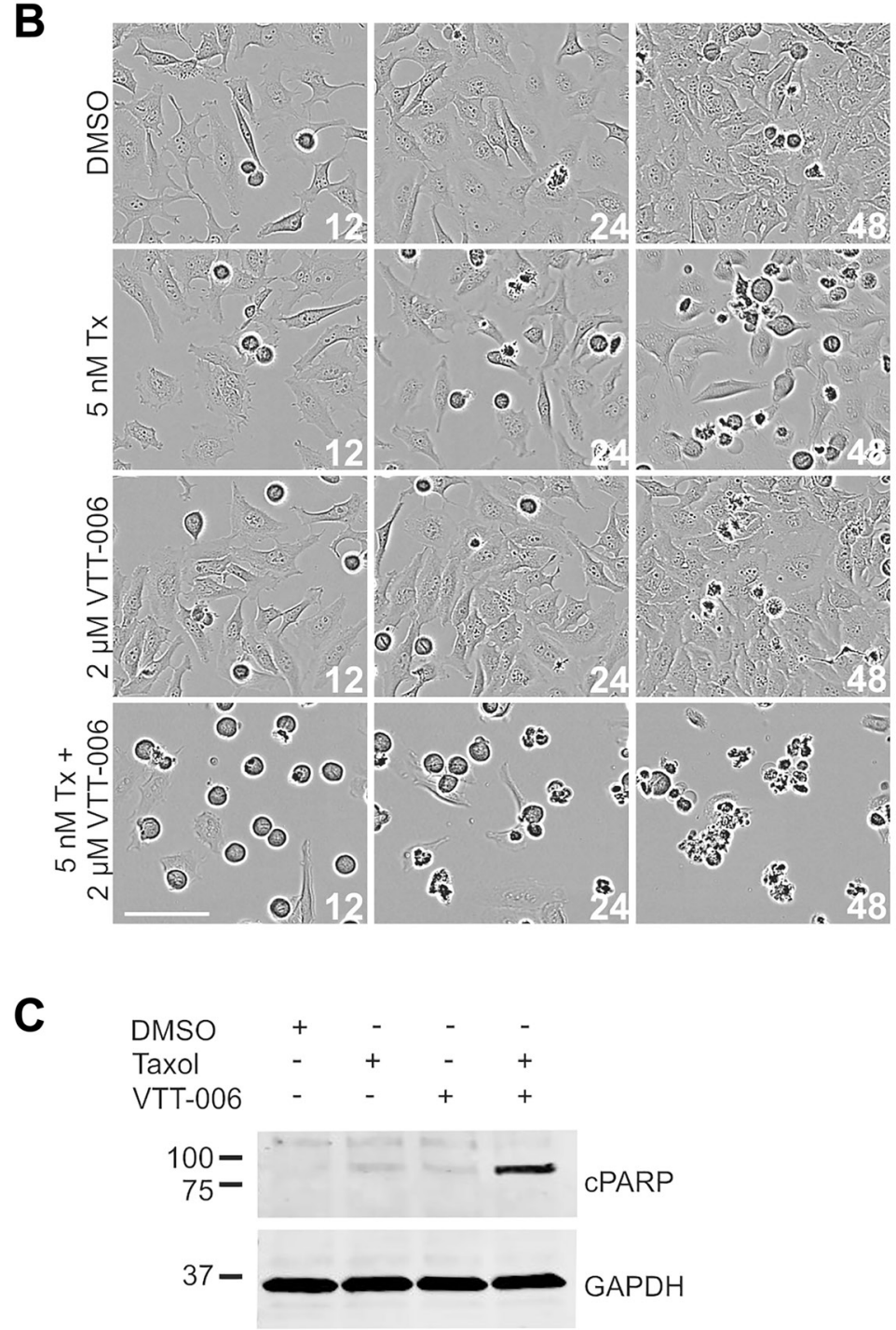

Figure 6: VTT-006 sensitizes HeLa cells to Taxol treatment. (A) Quantification of mitotic indices from IncuCyte films using varying concentrations of Taxol and VTT-006. Result is average \pm SD from 3 replicate experiments. One well ( $n \geq 250$ cells) was analysed in each experiment. (B) Representative images from IncuCyte films showing mitotic accumulation upon treatment with $5 \mathrm{nM}$ Taxol and $2 \mu \mathrm{M}$ VTT-006 alone or in combination. Time is indicated in $\mathrm{h}$ from the addition of the compounds. (C) Combination treatment increases cleaved PARP (cPARP) amount compared to single treatments. HeLa cells were treated with 5 nM Tx or $2 \mu \mathrm{M}$ VTT-006 alone or in combination for $24 \mathrm{~h}$, and collected for Western blot. Scale bar $=100 \mu \mathrm{m}$. 
Table 1: VTT-006 inhibits the proliferation of various cell lines

\begin{tabular}{lc}
\hline \multicolumn{1}{c}{ Cell line } & $\mathbf{E C}_{\mathbf{5 0}}(\boldsymbol{\mu M})$ \\
\hline Non-tumorigenic immortalized cell lines & $21.3 \pm 1.5$ \\
\hline MCF10A (mammary epithelial cells) & $5.7 \pm 1.0$ \\
Ep156T (prostate epithelial cells) & $4.8 \pm 0.5$ \\
RWPE-1 (prostate epithelial cells) & $6.5 \pm 1.3$ \\
\hline Tumorigenic cell lines & $8.3 \pm 1.7$ \\
\hline HeLa (cervical adenocarcinoma) & $4.9 \pm 1.5$ \\
MCF7 (breast adenocarcinoma) & $6.7 \pm 1.4$ \\
MDA-MB-231 (breast adenocarcinoma) & $8.1 \pm 2.0$ \\
MDA-MB-231-SA (breast adenocarcinoma) & $6.3 \pm 0.6$ \\
LnCaP (prostatic adenocarcinoma) & $10.4 \pm 0.5$ \\
RWPE-2-W99 (tumorigenic derivative of RWPE-1) & $11.9 \pm 0.9$ \\
HCT116 (colorectal adenocarcinoma) & $7.5 \pm 1.2$ \\
A549 (lung adenocarcinoma) & \\
\hline
\end{tabular}

Mean $\mathrm{EC}_{50}$ values $\pm \mathrm{SD}$ from 3 replicate experiments are shown.

inter-kinetochore tension and mitotic arrest in cells with mutations in Hec1 CHD at Lys residues 89, 115 and 116 [9], and the study by Sundin et al. reporting chromosome misalignment along with cold stable microtubules and reduced inter-kinetochore tension in cells with mutations in Hec1 binding partner Nuf2 CHD [34]. Thus, treatment of cells with VTT-006 produced a similar phenotype as mutation of key microtubule binding residues in the two CHDs of the Ndc80 complex. Lastly, chromosome movements including metaphase oscillations were clearly dampened in VTT-006 treated cells. Switches in chromosome movements originate from changes in kinetochore microtubule dynamics and kinetochore tension [55]. Interestingly, $\mathrm{Hec} 1$ has been reported to directly regulate microtubule dynamics [52]. In addition to this, the phosphorylation status of the tail region of $\mathrm{Hec} 1$ was shown to correlate with the amplitude of oscillation [56]. Together these data imply that the reduced metaphase plate oscillations observed in VTT-006 treated cells result from compound induced alterations in kinetochore microtubule dynamics and/or tension.

According to the analysis of time-lapse filmed cells, initial chromosome capture and lateral sliding along a microtubule soon after NEB appeared to be intact, which is in line with earlier findings showing Ndc80 is not required for lateral connections, which are thought to be mediated by dynein and Cenp-E [30, 32]. Moreover, all chromosomes in VTT-006 treated cells were capable of establishing connections with spindle microtubules as they exhibited movements in the vicinity of spindle poles or migrated to the metaphase plate. Importantly, the addition of VTT-006 on MG132 pre-treated metaphase cells led to a rapid impairment of metaphase chromosome alignment, which suggests that the defect in chromosome attachments also compromised the ability of cells to maintain amphitelic chromosome attachments. The extent of chromosome misalignment varied between individual cells and chromosomes within a cell. Some cells exhibited a few unaligned chromosomes while other chromosomes congressed to the metaphase plate. In some cells, most or all chromosomes remained unaligned after NEB until the cells died several hours later. At the moment we have no evidence-based explanation why some chromosomes are more sensitive to VTT-006 than others. This could reflect variability in the attachment dynamics between individual chromosomes to microtubules making them more or less vulnerable to VTT-006. Alternatively, there can be differences in the pharmacokinetics of VTT-006 at the level of individual kinetochores. For example, the accessibility or binding kinetics of the drug to its binding pocket may vary due to conformational differences between individual Ndc 80 complexes. We cannot rule out the possibility that the compound has also other targets, such as microtubules, that can contribute to the phenotype we observe. Future research is warranted to examine the effects of VTT-006 in the presence of mutated Hec1 to evaluate the specificity of the compound.

In summary, we propose that VTT-006 impairs normal kinetochore-microtubule interactions by causing intermittent defects in the attachment status of individual kinetochores. In early mitotic cells, this results in two phenomena depending on initial chromosome attachment; chromosomes that instantly achieve amphitelic attachments after NEB can congress, albeit with sluggish dynamics, to the metaphase plate whereas chromosomes that end up with syntelic attachments after NEB remain near the poles due to defects in the syntelic-to-amphitelic conversion process. However, our findings that addition 
of VTT-006 to metaphase cells causes loss of alignment would seemingly contradict this model. Possibly in cells arrested at metaphase, the sudden influx of VTT-006 may weaken the strength of normal amphitelic attachments by causing release of individual microtubules at the kinetochore-microtubule interface eventually leading to loss of bi-polar attachment and metaphase chromosome alignment. The two phenomena can also be explained by additional mitotic targets of the compound.

Cell growth suppressive effects of VTT-006 occurred at the micromolar range $\left(\mathrm{EC}_{50}\right.$ varied between 4.8 and $21.3 \mu \mathrm{M}$ ). Similarly, in the organotypic 3D culture of breast cancer cells, spheroid growth became limited at $5 \mu \mathrm{M}$ level. From a therapeutic perspective, this indicates a need for further chemical optimisation of VTT006 to achieve enhanced dose response without losing the demonstrated biological activity of the compound. Furthermore, future research should investigate in more detail the increased sensitivity to taxol induced by VTT006 and extend the studies to several cell lines. This is important for evaluating the possible advantage of combination treatment in taxol-resistant cells. Also, the absorption, distribution, metabolism, and excretion (ADME) properties of the compound must be improved prior to testing with tumour xenografts in mice. However, as is the compound will provide a useful experimental

\section{A}
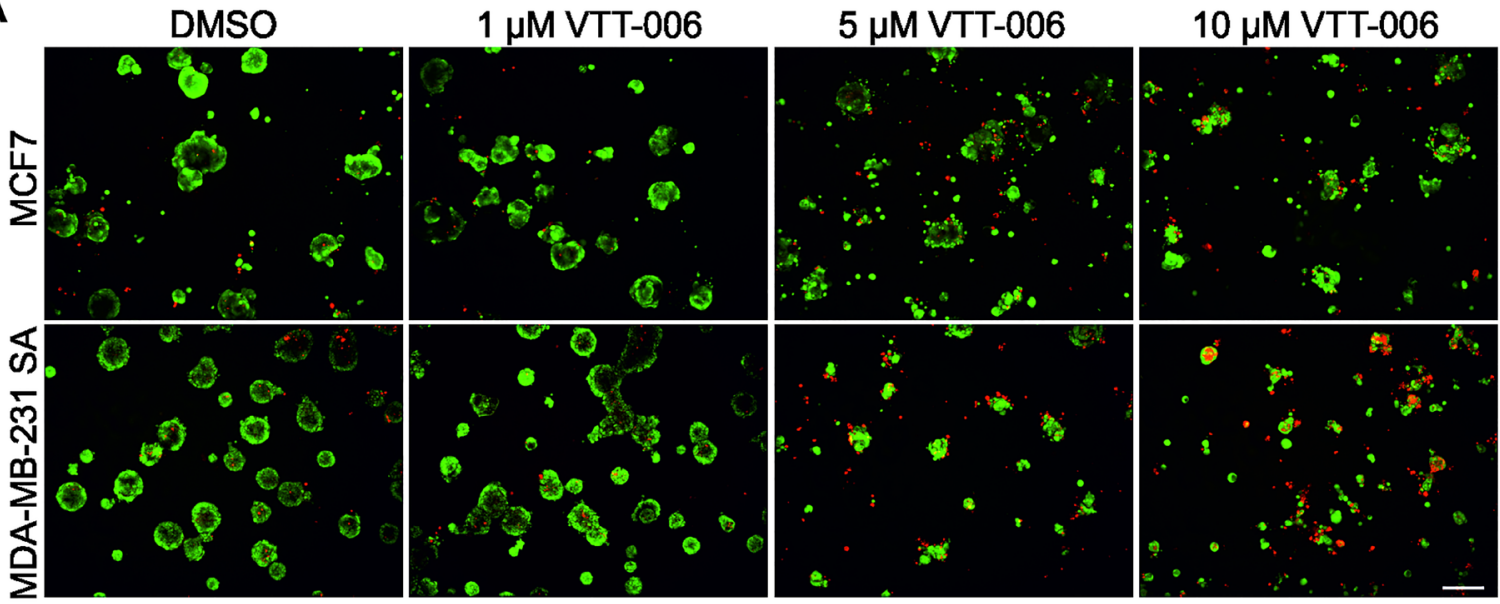

B
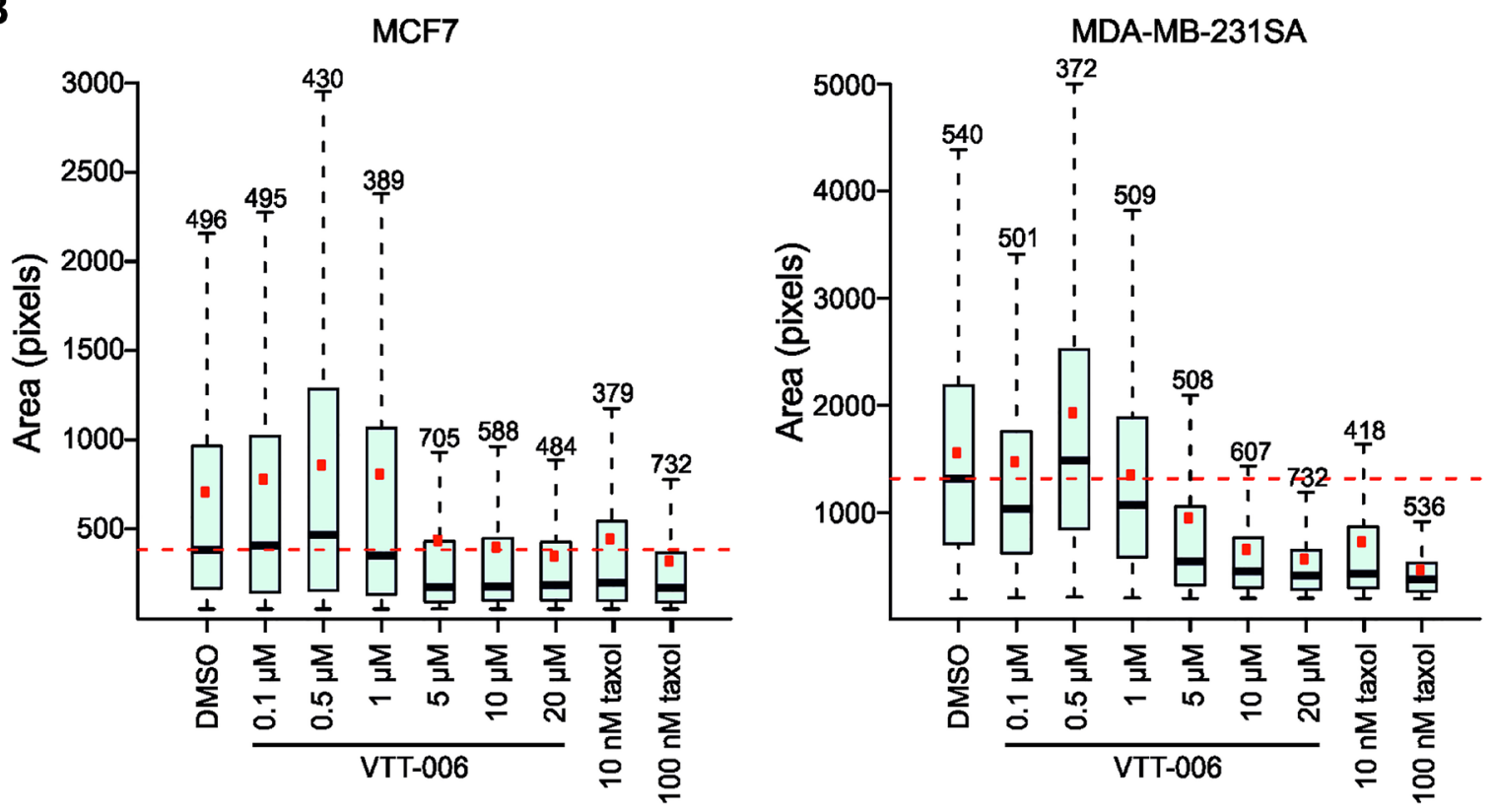

Figure 7: VTT-006 inhibits the growth of breast cancer cell lines in 3D organotypic cell cultures. (A) Representative images from 3D cell culture. MCF7 and MDA-MB-231 SA cells were treated with indicated compounds for 5-6 days and stained with calcein (green) to detect live cells and Ethidium homodimer-1 (red) to detect dead cells. (B) Quantification of spheroid size. Black line denotes median, red dot mean, box marks first and third quartiles and whiskers show the range of values. Size cut-off value of 50 was used for MCF7 and 200 for MDA-MB-231 SA analysis. Numbers on top of the dotted lines represent the number of spheroids ( $n$ ) analysed from each treatment. Scale bar $=200 \mu \mathrm{m}$. 
tool to inhibit $\mathrm{Ndc} 80$ complex function for cell and cancer biologists who are investigating mitotic processes.

\section{MATERIALS AND METHODS}

\section{Cell culture and reagents}

Growth conditions for the cell lines are described in Supplementary Materials and Methods. Nocodazole (Sigma, M1404), Taxol (Paclitaxel, Sigma, T7191), ZM447439 (Tocris Bioscience, 2458), and MG132 (Sigma, C2211) were used in the experiments at 0.5, $0.1,5$, and $20 \mu \mathrm{M}$ concentrations, respectively, unless indicated otherwise. Monastrol (Sigma, M8515) was used at $100 \mu \mathrm{M}$ concentration and staurosporine (Sigma, S5921) at $1 \mu \mathrm{M}$ concentration.

\section{Virtual screen}

Chemical vendor libraries of small molecules from Chembridge, Enamine, IBS, VitasM, Specs, LifeChem, Asinex and ChemDiv with pre-calculated 3D conformations were docked into the crystal structure of Ndc80 (PDB ID: 2IGP) [10]. Small molecules containing a nitro group and a molecular weight greater than 500 Dalton were excluded. The protein crystal structure was pre-treated in Sybyl (Tripos, L.P. St. Louis, MO, USA) by removing all water molecules, and adding hydrogen atoms to the protein in an orientation optimal for hydrogen bonding. Docking was performed with docking software FRED [26] (OpenEye Scientific Software Inc., Santa Fe, NM, USA). Each small molecule was docked with FRED's native function followed by re-scoring with five additional scoring functions: shapegauss, plp, chemgauss3, chemscore and screenscore. Each docking score was transformed into a Z-score by substracting the mean and dividing by the standard deviation of all docking scores of the respective scoring function. For the final hit list, molecules were taken that had a Z-score smaller than minus three with at least three scoring functions. These were still subjected to a visual inspection where improbable docking poses were excluded. In the end, we had 138 small molecules that were ordered from chemical suppliers. In addition to FRED software, VTT-006 docking was performed with Glide/Maestro package (version 9.6, Schrödinger Inc, Portland, OR, USA), which was used to create image in Figure 1C. Molecular Operating Environment (MOE) (2013.08; Chemical Computing Group Inc., Montreal, Canada) was used to create interaction maps (Figure 1D and Supplementary Figure 1).

\section{Cell based screen}

HeLa H2B-GFP [57] cells were plated on 384-well plates with a Multidrop Combi (Thermo Fisher Scientific,
Waltham, MA, USA) and selected compounds from the virtual screen were applied with Hamilton Microlab Star robotics (Hamilton, Reno, NV, USA) on cells, $24 \mathrm{~h}$ after seeding, in 3 different concentrations, $0.2,2$ and $20 \mu \mathrm{M}$. Taxol was used as a positive control as a mitotic arrest inducing compound at $3 \mu \mathrm{M}$ concentration and DMSO as negative control. The plates were imaged 18 and $42 \mathrm{~h}$ after compound addition using transmitted light and filter setting Alexa 488 to visualize GFP. Wells that had mitotic arrest were scored as positive hits.

\section{Anisotropy}

Fluorescence measurements were made on a QuantaMaster-1-spectrofluorometer operated in T-state (Photon Technology International, Lawrenceville, GA, USA). To determine excitation and emission properties of the compounds of interest excitation and emission spectra were collected at different wavelengths in PBS at $23^{\circ} \mathrm{C}$. The binding of the compounds to proteins was determined by measuring steady state anisotropy of the compound, and anisotropy in the presence of varying concentrations of Bonsai or Aurora B in PBS. Anisotropy measurements for VTT-006 were acquired using $350 \mathrm{~nm}$ for excitation and $450 \mathrm{~nm}$ for emission. The dissociation constant $\left(\mathrm{K}_{\mathrm{d}}\right)$ was calculated using a one site binding model that accounts for ligand depletion as previously described $[58,59]$. The data analysis and fitting was done with the Microcal Origin 7.5 software (Origin Lab, Northampton, MA, USA).

\section{Recombinant protein production}

$\mathrm{Ndc} 80^{\text {bonsai }}$ (referred to as Bonsai) was a kind gift from A. Musacchio [11]. For anisotropy, Bonsai was purified as described below. Bonsai expression in $E$. coli BL21(DE3) was induced with $500 \mu \mathrm{M}$ IPTG at $\mathrm{OD}_{600}=0.45-0.7$ for $16 \mathrm{~h}$ at RT. Cells were harvested by centrifugation at $3500 \mathrm{~g}$. The bacterial pellet was resuspended in lysis buffer $(50 \mathrm{mM}$ Tris- $\mathrm{HCl}, \mathrm{pH} 7.6,300$ $\mathrm{mM} \mathrm{NaCl}, 1 \mathrm{mM}$ DTT, 1 mM EDTA, Complete Protease Inhibitor Cocktail Tablets from Roche) and sonicated. After this, lysate was cleared by centrifugation at $50000 \times \mathrm{g}$ for $60 \mathrm{~min}$. Supernatant was filtered and Bonsai purified using ÄKTA prime plus system (GE Healthcare, Waukesha, WI, USA) and GST Sepharose Fast Flow (GE Healthcare). Cleavage buffer (50 mM Tris-HCl, $\mathrm{pH} 7.6$, $150 \mathrm{mM} \mathrm{NaCl}, 1 \mathrm{mM}$ DTT, $1 \mathrm{mM}$ EDTA) was used for equilibration and elution of Bonsai. PreScission protease (GE Healthcare) was applied into the column and left overnight at $+4^{\circ} \mathrm{C}$ to cleave off GST followed by elution of Bonsai. Fractions containing Bonsai were collected and used for anisotropy. For GST-Aurora B production, BaculoGold $^{\mathrm{TM}}$ expression system (BD Biosciences) was used to express Aurora B in Sf9 insect cells as described previously [60]. 


\section{TIRF microscopy}

Total internal reflection fluorescence (TIRF) microscopy was performed on a custom illumination system as previously described $[52,61,62]$. Recombinant GFPtagged Ndc80 complex used for TIRF was expressed and purified as previously described $[52,63]$. Taxol-stabilized microtubules (1\% Alexa-568-labeled) were bound to coverslips using a "rigor" kinesin [64]. GFP-tagged Ndc80 complex was assayed at 6-10 pM in BRB80 (80 mM Pipes, $120 \mathrm{mM} \mathrm{K}^{+}, 1 \mathrm{mM} \mathrm{MgCl}_{2}$, and $1 \mathrm{mM}$ EGTA, pH 6.9) with $8 \mathrm{mg} / \mathrm{mL}$ BSA, $10 \mu \mathrm{M}$ Taxol, and an oxygen scavenger system $(200 \mu \mathrm{g} / \mathrm{mL}$ glucose oxidase, $35 \mu \mathrm{g} / \mathrm{mL}$ catalase, $25 \mathrm{mM}$ glucose, and $5 \mathrm{mM}$ DTT). VTT-006 was assayed at $10 \mu \mathrm{M}$, and DMSO was used as a control. Analysis of TIRF microscopy data was performed using custom software (available upon request) in LabVIEW (National Instruments, Austin, TX, USA) and Igor Pro (Wavemetrics, Tigard, OR, USA), as previously described [61].

\section{Immunofluorescence}

For immunofluorescence, cells growing on coverslips were fixed for $15 \mathrm{~min}$ in $60 \mathrm{mM}$ Pipes, $\mathrm{pH}$ 6.9, $25 \mathrm{mM}$ Hepes, $10 \mathrm{mM}$ EGTA, $4 \mathrm{mM}$ MgSO4 (PHEM) containing $2 \%$ paraformaldehyde, $0.2 \%$ glutaraldehyde (added for tubulin staining), and $0.5 \%$ Triton X-100. The coverslips were rinsed in $10 \mathrm{mM}$ MOPS, $\mathrm{pH} 7.4$, $150 \mathrm{mM} \mathrm{NaCl}, 0.05 \%$ Tween-20 (MBST), and blocked for $1 \mathrm{~h}$ in $20 \%$ boiled normal goat serum (bngs) in MBST. Cells were stained for $1 \mathrm{~h}$ at RT or overnight at $+4^{\circ} \mathrm{C}$ with primary antibodies against Aurora B (AIM1, BD, 611083), phospho-Thr232 (Rockland 600-401677), Bub1 (Upstate, 05-899), BuBR1 (Abcam, ab4637), Hec1 (Abcam, ab3613), pericentrin (Abcam, ab4448), tubulin (Abcam, ab7291) or human autoimmune serum (Crest, Antibodies Incorporated) followed by Alexa Fluor 488, 555 and 647 dyes against mouse, rabbit and human antigens (Invitrogen) diluted in MBST. DNA was counter stained with DAPI before mounting in Vectashield (Vector laboratories, $\mathrm{H}-1000)$. The cold- $\mathrm{Ca}^{++}$assay to analyze the stability of kinetochore-microtubule attachment was performed by placing coverslips in ice cold lysis buffer (0.1 M Pipes, pH 6.95, $80 \mu \mathrm{M} \mathrm{CaCl}_{2}, 1 \%$ Triton X-100) for 5 minutes followed by fixation for tubulin staining.

\section{Microscopy}

ScanR high content imager (Olympus Corporation, Tokyo, Japan) equipped with a Hamamatsu ORCA-ER CCD digital camera (Hamamatsu Photonics, Hamamatsu City, Japan) was used to analyze cell-based screen results. Live cell phase-contrast imaging was performed with an IncuCyte live-cell imager (Essen Instruments Ltd., Hertfordshire, UK). A Zeiss inverted 200M microscope (Zeiss GmbH, Jena, Germany) equipped with a Hamamatsu ORCA-ER camera and MetaMorph software (Molecular Devices, Downingtown, USA) was used for analysis of kinetochore protein levels. Kinetochore intensities were quantified from maximum projections created from a Z-stack of images acquired every $0.5 \mu \mathrm{m}$. Zeiss Axiovert 200M microscope equipped with spinning disk CSU22 confocal scanner (Yokogawa, Tokyo, Japan) and SlideBook 5.0 software (Intelligent Imaging Innovations, Inc. Denver, CO, USA) was used for acquiring images of 3D cultures, for the analysis of kinetochore distances and live-cell imaging of Hela H2BGFP and GFP-Spc24 HeLas with environmental control.

\section{Western blotting}

HeLa cells were centrifuged and washed once with cold PBS before preparation of extract or freezing the pellets in liquid nitrogen. For the preparation of extracts, cells were lysed in $20 \mathrm{mM}$ Tris- $\mathrm{HCl}(\mathrm{pH} 7.7), 100 \mathrm{mM}$ $\mathrm{KCl}, 50 \mathrm{mM}$ sucrose, $1 \mathrm{mM} \mathrm{MgCl}_{2}, 0.1 \mathrm{mM} \mathrm{CaCl}_{2}$, $0.5 \%$ TX-100 (APC-buffer) containing protease inhibitor cocktail (Roche, 04693132001) and phosphatase inhibitor PhosSTOP (Roche, 4906837001) for $7 \mathrm{~min}$ on ice, and cell lysates were cleared by centrifugation. Equal amounts of samples were loaded and run on 4-20\% gradient gels followed by semi-dry transfer with Trans-blot (Bio-Rad, Hercules, CA). Membranes were blocked in 5\% milk or Odyssey blocking buffer (Fisher Scientific, NC9877369) in TBS for $1 \mathrm{~h}$, followed by primary antibody incubation for $1 \mathrm{~h}$ at RT or overnight at $+4^{\circ} \mathrm{C}$ in TBST (TBS containing $0.05 \%$ Tween), and secondary antibody for $1 \mathrm{~h}$ at RT in TBST. Primary antibodies against Hec1 (Abcam, ab3613), cleaved PARP (Cell Signaling, 9546, dilution) and GAPDH (Advanced ImmunoChemical Inc., mAb 6C5) were followed by secondary antibody Alexa Fluor $^{\circledR}$ anti-mouse 680 (Invitrogen). Signals were detected using Odyssey Infrared Imaging System (LI-COR Biosciences, Lincoln, NE, USA).

\section{In vitro tubulin polymerization assay}

Fluorescence in vitro tubulin polymerization assay (Cytoskeleton Inc., BK011) was performed according to the manufacturer's instructions. The reaction contained PEM buffer, glycerol (13.8\%), GTP (1 mM), porcine brain $>99 \%$ pure tubulin $(2 \mathrm{mg} / \mathrm{ml})$, fluorescent reporter $(5 \mu \mathrm{M})$, and test compounds. Taxol $(3 \mu \mathrm{M})$, vinblastine $(3 \mu \mathrm{M})$ and DMSO were used as controls. Tubulin polymerization reaction was measured at $1 \mathrm{~min}$ intervals for $60 \mathrm{~min}$ at $37^{\circ} \mathrm{C}$ with excitation at $355 \mathrm{~nm}$ and emission at $460 \mathrm{~nm}$ with Victor 1420 Multilabel HTS Counter (Perkin Elmer, Waltham, MA, USA).

\section{D organotypic cell culture}

3D cell culture was performed with some modifications to the previously described protocol [40]. A bottom gel (4 mg/ml) was prepared with growth factor reduced and phenol-red free Matrigel (BD Biosciences, 356231) in RPMI 1640 and pipetted to the wells of tissue 
culture treated Angiogenesis 96-well plates (Ibidi Gmbh, Planegg/Martinsried, Germany, cat. no 89646). Plates were centrifuged for $20 \mathrm{~min}$ at $200 \mathrm{rpm}$ and allowed to polymerize at $37^{\circ} \mathrm{C}$ for $1 \mathrm{~h}$. Cells were collected by trypsin and mixed with Matrigel $(2 \mathrm{mg} / \mathrm{ml})$ in growth medium and applied to wells with cell density of 1000-1500 cells/well. This upper gel containing cells was allowed to polymerize for $3 \mathrm{~h}$ to overnight at $37^{\circ} \mathrm{C}$ before medium was added to wells. Growth media recipes are described in Supplementary Materials and Methods. MCF7 cells were grown until day 6 before DMSO, VTT-006 or Taxol were added and cells were grown in the presence of the compounds for 6 days. MDA-MB-231 SA cells were incubated with compounds for 5 days starting at day 2. Drugs were applied to cells at different time points when spheroid size was optimal and fresh medium with drugs was changed every $2-3$ days. Treatments were performed in triplicate.

\section{D image acquisition and analysis}

Multicellular structures were double-stained with Calcein-AM fluorescent dye (Molecular Probes, C1430) and Ethidium homodimer-1 (Molecular Probes, E1169). 3D confocal images were acquired using Zeiss Plan-Neofluar $5 \mathrm{x}$ objective. Maximum intensity projections were created and background noise was removed by normalization with SlideBook. Images were analyzed using VTT's inhouse developed proprietary software AMIDA, software specifically designed for multicellular structure segmentation and measurement of biologically important morphological features such as size, roundness and cellular invasiveness [65]. All statistical analyses and plotting of numerical data (post-image analysis) were performed using $\mathrm{R}$, an open source programming language and software environment for statistical computing and graphics (http://cran.r-project.org).

\section{Measurement of $\mathbf{E C}_{50}$ values}

Cells were plated on 384-well plates with Multidrop Combi (Thermo Scientific, Waltham, USA). VTT-006 was added to cells $24 \mathrm{~h}$ later at 7 different concentrations between $1 \mathrm{nM}-20 \mu \mathrm{M}$ in 6 replicate wells per concentration. CellTiter Glo reagent (Promega) was added to cells following manufacturer's protocol at 48 or $72 \mathrm{~h}$ and cell viability was analyzed with Envision 2100 multilabel plate reader (Perkin Elmer, Waltham, MA, USA) by measuring luminescence. Data analysis was performed with Graph Pad Prism 4 (GraphPad Software, Inc, La Jolla, CA, USA). $\mathrm{EC}_{50}$ values were determined from 3 replicate experiments.

\section{Abbreviations}

ADME: Absorption, Distribution, Metabolism, And Excretion; Bngs: Boiled normal goat serum; BSA: Bovine Serum Albumin; CHD: Calponin Homology Domain; DAPI: 4',6-diamidino-2-phenylindole; DMSO: dimethyl sulfoxide; DNA: deoxyribonucleic acid; DTT: dithiothreitol; GAPDH: glyceraldehyde-3-phosphate dehydrogenase; GFP: Green Fluorescent Protein; Hec1: highly expressed in cancer 1; HTS: high-throughput screen; MOE: Molecular Operating Environment; NEB: Nuclear Envelope Breakdown; PARP: poly (ADP-ribose) polymerase; PBS: Phosphate Buffered Saline; RNA: ribonucleic acid; RNAi: RNA interference; siRNA: small interfering RNA; TIRF: Total Internal Reflection Fluorescence.

\section{Author contributions}

LL and JM-J were responsible for the study planning, execution of laboratory experiments and writing the manuscript. EK performed chromosome congression and oscillations measurements. PT and AP performed the virtual screen of the compounds. TN performed the anisotropy measurements. JT, NU, TD and CA performed TIRF microscopy experiments. VH performed 3D cultures and 3D image acquisition and analysis. LK and MK were responsible for the study planning as well as research group funding and facilities. LK, MK and GJG contributed to the writing of the manuscript.

\section{ACKNOWLEDGMENTS}

We are grateful to people who provided cell lines: Professors G.J. Gorbsky, P.T. Stukenberg, T.A. Guise, V. Rotter and L. Aaltonen. A. Musacchio is acknowledged for sending Bonsai plasmid.

\section{CONFLICTS OF INTEREST}

The authors have no conflicts of interest to declare.

\section{FUNDING}

This study was supported by Academy of Finland grants 120804 to M.J. Kallio and 134272 to L.J. Laine, Marie Curie EXT grant 002697 to M.J. Kallio, the Academy of Finland Centre of Excellence for Translational Genome-Scale Biology funding for M.J. Kallio, P. Tiikkainen, and L. Kallio, the Finnish Cancer Organisations grants to M.J. Kallio and J.H.E. MäkiJouppila, FinPharma Doctoral Program funding for J.H.E. Mäki-Jouppila, and Finnish Cultural Foundation grant to J.H.E. Mäki-Jouppila. T. Nyholm was funded by the Academy of Finland, V. Härmä by Predect and A. Poso by the University of Eastern Finland, School of Pharmacy.

\section{REFERENCES}

1. DeLuca JG, Dong Y, Hergert P, Strauss J, Hickey JM, Salmon ED, McEwen BF. Hec1 and nuf2 are core 
components of the kinetochore outer plate essential for organizing microtubule attachment sites. Mol Biol Cell. 2005; 16:519-31. https://doi.org/10.1091/mbc.e04-09-0852. PMID:15548592

2. Ciferri C, Musacchio A, Petrovic A. The Ndc80 complex: hub of kinetochore activity. FEBS Lett. 2007; 581:2862-69. https://doi.org/10.1016/j.febslet.2007.05.012. PMID:17521635

3. Hori T, Haraguchi T, Hiraoka Y, Kimura H, Fukagawa T. Dynamic behavior of Nuf2-Hec1 complex that localizes to the centrosome and centromere and is essential for mitotic progression in vertebrate cells. J Cell Sci. 2003; 116:334762. https://doi.org/10.1242/jcs.00645. PMID:12829748

4. Cheeseman IM, Chappie JS, Wilson-Kubalek EM, Desai A. The conserved KMN network constitutes the core microtubule-binding site of the kinetochore. Cell. 2006; 127:983-97. https://doi.org/10.1016/j.cell.2006.09.039. PMID:17129783

5. McCleland ML, Kallio MJ, Barrett-Wilt GA, Kestner CA, Shabanowitz J, Hunt DF, Gorbsky GJ, Stukenberg PT. The vertebrate Ndc80 complex contains Spc24 and Spc25 homologs, which are required to establish and maintain kinetochore-microtubule attachment. Curr Biol. 2004; 14:131-37. $\quad$ https://doi.org/10.1016/j.cub.2003.12.058. PMID:14738735

6. McCleland ML, Gardner RD, Kallio MJ, Daum JR, Gorbsky GJ, Burke DJ, Stukenberg PT. The highly conserved Ndc80 complex is required for kinetochore assembly, chromosome congression, and spindle checkpoint activity. Genes Dev. 2003; 17:101-14. https://doi.org/10.1101/gad.1040903. PMID:12514103

7. DeLuca JG, Moree B, Hickey JM, Kilmartin JV, Salmon ED. hNuf2 inhibition blocks stable kinetochore-microtubule attachment and induces mitotic cell death in HeLa cells. J Cell Biol. 2002; 159:549-55. https://doi.org/10.1083/ jcb.200208159. PMID: 12438418

8. DeLuca JG, Howell BJ, Canman JC, Hickey JM, Fang G, Salmon ED. Nuf2 and $\mathrm{Hec} 1$ are required for retention of the checkpoint proteins Mad1 and Mad2 to kinetochores. Curr Biol. 2003; 13:2103-09. https://doi.org/10.1016/j. cub.2003.10.056. PMID:14654001

9. Tooley JG, Miller SA, Stukenberg PT. The Ndc80 complex uses a tripartite attachment point to couple microtubule depolymerization to chromosome movement. Mol Biol Cell. 2011; 22:1217-26. https://doi.org/10.1091/mbc.E1007-0626. PMID:21325630

10. Wei RR, Al-Bassam J, Harrison SC. The Ndc80/HEC1 complex is a contact point for kinetochore-microtubule attachment. Nat Struct Mol Biol. 2007; 14:54-59. https:// doi.org/10.1038/nsmb1186. PMID: 17195848

11. Ciferri C, Pasqualato S, Screpanti E, Varetti G, Santaguida S, Dos Reis G, Maiolica A, Polka J, De Luca JG, De Wulf P, Salek M, Rappsilber J, Moores CA, et al. Implications for kinetochore-microtubule attachment from the structure of an engineered Ndc80 complex. Cell. 2008; 133:427-39. https://doi.org/10.1016/j.cell.2008.03.020. PMID:18455984

12. Guimaraes GJ, Dong Y, McEwen BF, Deluca JG. Kinetochore-microtubule attachment relies on the disordered N-terminal tail domain of Hec1. Curr Biol. 2008; 18:1778-84. https://doi.org/10.1016/j.cub.2008.08.012. PMID:19026543

13. Miller SA, Johnson ML, Stukenberg PT. Kinetochore attachments require an interaction between unstructured tails on microtubules and $\mathrm{Ndc} 80(\mathrm{Hec} 1)$. Curr Biol. 2008; 18:1785-91. https://doi.org/10.1016/j.cub.2008.11.007. PMID:19026542

14. DeLuca JG, Gall WE, Ciferri C, Cimini D, Musacchio A, Salmon ED. Kinetochore microtubule dynamics and attachment stability are regulated by Hec1. Cell. 2006; 127:969-82. https://doi.org/10.1016/j.cell.2006.09.047. PMID: 17129782

15. DeLuca KF, Lens SM, DeLuca JG. Temporal changes in Hec1 phosphorylation control kinetochore-microtubule attachment stability during mitosis. J Cell Sci. 2011; 124:622-34. https:// doi.org/10.1242/jcs.072629. PMID:21266467

16. Wei R, Ngo B, Wu G, Lee WH. Phosphorylation of the Ndc80 complex protein, HEC1, by Nek2 kinase modulates chromosome alignment and signaling of the spindle assembly checkpoint. Mol Biol Cell. 2011; 22:3584-94. https://doi.org/10.1091/mbc.E11-01-0012. PMID:21832156

17. Chen Y, Riley DJ, Zheng L, Chen PL, Lee WH. Phosphorylation of the mitotic regulator protein $\mathrm{Hec} 1$ by Nek2 kinase is essential for faithful chromosome segregation. J Biol Chem. 2002; 277:49408-16. https://doi. org/10.1074/jbc.M207069200. PMID:12386167

18. Kemmler S, Stach M, Knapp M, Ortiz J, Pfannstiel J, Ruppert T, Lechner J. Mimicking Ndc80 phosphorylation triggers spindle assembly checkpoint signalling. EMBO J. 2009; 28:1099-110. https://doi.org/10.1038/emboj.2009.62. PMID:19300438

19. Gurzov EN, Izquierdo M. RNA interference against Hec1 inhibits tumor growth in vivo. Gene Ther. 2006; 13:1-7. https://doi.org/10.1038/sj.gt.3302595. PMID:16121206

20. Li L, Yang L, Scudiero DA, Miller SA, Yu ZX, Stukenberg PT, Shoemaker RH, Kotin RM. Development of recombinant adeno-associated virus vectors carrying small interfering RNA ( $\mathrm{shHec} 1)$-mediated depletion of kinetochore Hec1 protein in tumor cells. Gene Ther. 2007; 14:814-27. https://doi.org/10.1038/sj.gt.3302933. PMID: 17330085

21. Bièche I, Vacher S, Lallemand F, Tozlu-Kara S, Bennani H, Beuzelin M, Driouch K, Rouleau E, Lerebours F, Ripoche H, Cizeron-Clairac G, Spyratos F, Lidereau R. Expression analysis of mitotic spindle checkpoint genes in breast carcinoma: role of NDC80/HEC1 in early breast tumorigenicity, and a two-gene signature for aneuploidy. Mol Cancer. 2011; 10:23. https://doi.org/10.1186/14764598-10-23. PMID:21352579 
22. Wu G, Qiu XL, Zhou L, Zhu J, Chamberlin R, Lau J, Chen PL, Lee WH. Small molecule targeting the Hec1/Nek2 mitotic pathway suppresses tumor cell growth in culture and in animal. Cancer Res. 2008; 68:8393-99. https://doi. org/10.1158/0008-5472.CAN-08-1915. PMID:18922912

23. Qiu XL, Li G, Wu G, Zhu J, Zhou L, Chen PL, Chamberlin AR, Lee WH. Synthesis and biological evaluation of a series of novel inhibitor of Nek2/Hec1 analogues. J Med Chem. 2009; 52:1757-67. https://doi.org/10.1021/jm8015969. PMID:19243176

24. Huang LY, Lee YS, Huang JJ, Chang CC, Chang JM, Chuang SH, Kao KJ, Tsai YJ, Tsai PY, Liu CW, Lin HS, Lau JY. Characterization of the biological activity of a potent small molecule Hec1 inhibitor TAI-1. J Exp Clin Cancer Res. 2014; 33:6. https://doi.org/10.1186/1756-996633-6. PMID:24401611

25. Ferrara M, Sessa G, Fiore M, Bernard F, Asteriti IA, Cundari E, Colotti G, Ferla S, Desideri M, Buglioni S, Trisciuoglio D, Del Bufalo D, Brancale A, Degrassi F. Small molecules targeted to the microtubule-Hec1 interaction inhibit cancer cell growth through microtubule stabilization. Oncogene. 2018; 37:231-40. https://doi.org/10.1038/onc.2017.320. PMID:28925395

26. McGann M. FRED pose prediction and virtual screening accuracy. J Chem Inf Model. 2011; 51:578-96. https://doi. org/10.1021/ci100436p. PMID:21323318

27. Musacchio A, Salmon ED. The spindle-assembly checkpoint in space and time. Nat Rev Mol Cell Biol. 2007; 8:379-93. https://doi.org/10.1038/nrm2163. PMID:17426725

28. Logarinho E, Bousbaa H, Dias JM, Lopes C, Amorim I, Antunes-Martins A, Sunkel CE. Different spindle checkpoint proteins monitor microtubule attachment and tension at kinetochores in Drosophila cells. J Cell Sci. 2004; 117:1757-71. https://doi.org/10.1242/jcs.01033. PMID:15075237

29. Skoufias DA, Andreassen PR, Lacroix FB, Wilson L, Margolis RL. Mammalian mad2 and bub1/bubR1 recognize distinct spindle-attachment and kinetochore-tension checkpoints. Proc Natl Acad Sci U S A. 2001; 98:4492-97. https://doi.org/10.1073/pnas.081076898. PMID:11274370

30. Kapoor TM, Lampson MA, Hergert P, Cameron L, Cimini D, Salmon ED, McEwen BF, Khodjakov A. Chromosomes can congress to the metaphase plate before biorientation. Science. 2006; 311:388-91. https://doi.org/10.1126/ science.1122142. PMID:16424343

31. Magidson $\mathrm{V}$, O'Connell $\mathrm{CB}$, Lončarek $\mathrm{J}$, Paul $\mathrm{R}$, Mogilner A, Khodjakov A. The spatial arrangement of chromosomes during prometaphase facilitates spindle assembly. Cell. 2011; 146:555-67. https://doi.org/10.1016/j. cell.2011.07.012. PMID:21854981

32. Vorozhko VV, Emanuele MJ, Kallio MJ, Stukenberg PT, Gorbsky GJ. Multiple mechanisms of chromosome movement in vertebrate cells mediated through the Ndc80 complex and dynein/dynactin. Chromosoma. 2008; 117:169-79. https:// doi.org/10.1007/s00412-007-0135-3. PMID:18057949
33. Maure JF, Komoto S, Oku Y, Mino A, Pasqualato S, Natsume K, Clayton L, Musacchio A, Tanaka TU. The Ndc80 loop region facilitates formation of kinetochore attachment to the dynamic microtubule plus end. Curr Biol. 2011; 21:207-13. https://doi.org/10.1016/j. cub.2010.12.050. PMID:21256019

34. Sundin LJ, Guimaraes GJ, Deluca JG. The NDC80 complex proteins Nuf2 and Hec1 make distinct contributions to kinetochore-microtubule attachment in mitosis. Mol Biol Cell. 2011; 22:759-68. https://doi.org/10.1091/mbc.E1008-0671. PMID:21270439

35. Hewitt L, Tighe A, Santaguida S, White AM, Jones CD, Musacchio A, Green S, Taylor SS. Sustained Mps 1 activity is required in mitosis to recruit O-Mad2 to the Mad1-CMad2 core complex. J Cell Biol. 2010; 190:25-34. https:// doi.org/10.1083/jcb.201002133. PMID:20624899

36. Hauf S, Cole RW, LaTerra S, Zimmer C, Schnapp G, Walter R, Heckel A, van Meel J, Rieder CL, Peters JM. The small molecule Hesperadin reveals a role for Aurora $\mathrm{B}$ in correcting kinetochore-microtubule attachment and in maintaining the spindle assembly checkpoint. J Cell Biol. 2003; 161:281-94. https://doi.org/10.1083/jcb.200208092. PMID:12707311

37. Ditchfield C, Johnson VL, Tighe A, Ellston R, Haworth C, Johnson T, Mortlock A, Keen N, Taylor SS. Aurora B couples chromosome alignment with anaphase by targeting BubR1, Mad2, and Cenp-E to kinetochores. J Cell Biol. 2003; 161:267-80. https://doi.org/10.1083/jcb.200208091. PMID: 12719470

38. Yasui Y, Urano T, Kawajiri A, Nagata K, Tatsuka M, Saya H, Furukawa K, Takahashi T, Izawa I, Inagaki M. Autophosphorylation of a newly identified site of Aurora-B is indispensable for cytokinesis. J Biol Chem. 2004; 279:12997-3003. https://doi.org/10.1074/jbc.M311128200. PMID:14722118

39. Mo QQ, Chen PB, Jin X, Chen Q, Tang L, Wang BB, Li KZ, Wu P, Fang Y, Wang SX, Zhou JF, Ma D, Chen G. Inhibition of $\mathrm{Hec} 1$ expression enhances the sensitivity of human ovarian cancer cells to paclitaxel. Acta Pharmacol Sin. 2013; 34:541-48. https://doi.org/10.1038/aps.2012.197. PMID:23474708

40. Härmä V, Virtanen J, Mäkelä R, Happonen A, Mpindi JP, Knuuttila M, Kohonen P, Lötjönen J, Kallioniemi O, Nees M. A comprehensive panel of three-dimensional models for studies of prostate cancer growth, invasion and drug responses. PLoS One. 2010; 5:e10431. https://doi. org/10.1371/journal.pone.0010431. PMID:20454659

41. Dumontet C, Jordan MA. Microtubule-binding agents: a dynamic field of cancer therapeutics. Nat Rev Drug Discov. 2010; 9:790-803. https://doi.org/10.1038/nrd3253. PMID:20885410

42. Jones R, Vuky J, Elliott T, Mead G, Arranz JA, Chester J, Chowdhury S, Dudek AZ, Müller-Mattheis V, Grimm MO, Gschwend JE, Wülfing C, Albers P, et al. Phase II study to assess the efficacy, safety and tolerability of the 
mitotic spindle kinesin inhibitor AZD4877 in patients with recurrent advanced urothelial cancer. Invest New Drugs. 2013; 31:1001-07. https://doi.org/10.1007/s10637-0139926-y. PMID:23329066

43. Chung V, Heath EI, Schelman WR, Johnson BM, Kirby LC, Lynch KM, Botbyl JD, Lampkin TA, Holen KD. Firsttime-in-human study of GSK923295, a novel antimitotic inhibitor of centromere-associated protein E (CENP-E), in patients with refractory cancer. Cancer Chemother Pharmacol. 2012; 69:733-41. https://doi.org/10.1007/ s00280-011-1756-Z. PMID:22020315

44. Gjertsen BT, Schöffski P. Discovery and development of the Polo-like kinase inhibitor volasertib in cancer therapy. Leukemia. 2015; 29:11-19. https://doi.org/10.1038/ leu.2014.222. PMID:25027517

45. Müller-Tidow C, Bug G, Lübbert M, Krämer A, Krauter J, Valent P, Nachbaur D, Berdel WE, Ottmann OG, Fritsch H, Munzert G, Garin-Chesa P, Fleischer F, et al. A randomized, open-label, phase I/II trial to investigate the maximum tolerated dose of the Polo-like kinase inhibitor BI 2536 in elderly patients with refractory/relapsed acute myeloid leukaemia. Br J Haematol. 2013; 163:214-22. https://doi. org/10.1111/bjh.12518. PMID:24033250

46. Foran J, Ravandi F, Wierda W, Garcia-Manero G, Verstovsek S, Kadia T, Burger J, Yule M, Langford G, Lyons J, Ayrton J, Lock V, Borthakur G, et al. A phase I and pharmacodynamic study of AT9283, a small-molecule inhibitor of aurora kinases in patients with relapsed/ refractory leukemia or myelofibrosis. Clin Lymphoma Myeloma Leuk. 2014; 14:223-30. https://doi.org/10.1016/j. clml.2013.11.001. PMID:24355079

47. Seymour JF, Kim DW, Rubin E, Haregewoin A, Clark J, Watson P, Hughes T, Dufva I, Jimenez JL, Mahon FX, Rousselot P, Cortes J, Martinelli G, et al. A phase 2 study of MK-0457 in patients with BCR-ABL T315I mutant chronic myelogenous leukemia and philadelphia chromosomepositive acute lymphoblastic leukemia. Blood Cancer J. 2014; 4:e238. https://doi.org/10.1038/bcj.2014.60. PMID:25127392

48. Richardson PG, Baz R, Wang M, Jakubowiak AJ, Laubach JP, Harvey RD, Talpaz M, Berg D, Liu G, Yu J, Gupta N, Di Bacco A, Hui AM, Lonial S. Phase 1 study of twice-weekly ixazomib, an oral proteasome inhibitor, in relapsed/refractory multiple myeloma patients. Blood. 2014; 124:1038-46. https://doi.org/10.1182/ blood-2014-01-548826. PMID:24920586

49. Lendvai N, Hilden P, Devlin S, Landau H, Hassoun H, Lesokhin AM, Tsakos I, Redling K, Koehne G, Chung DJ, Schaffer WL, Giralt SA. A phase 2 single-center study of carfilzomib $56 \mathrm{mg} / \mathrm{m} 2$ with or without lowdose dexamethasone in relapsed multiple myeloma. Blood. 2014; 124:899-906. https://doi.org/10.1182/ blood-2014-02-556308. PMID:24963043

50. Diaz-Rodríguez E, Sotillo R, Schvartzman JM, Benezra R. Hecl overexpression hyperactivates the mitotic checkpoint and induces tumor formation in vivo. Proc Natl Acad Sci
U S A. 2008; 105:16719-24. https://doi.org/10.1073/ pnas.0803504105. PMID:18940925

51. Labrou N, Clonis YD. The affinity technology in downstream processing. J Biotechnol. 1994; 36:95-119. https://doi. org/10.1016/0168-1656(94)90047-7. PMID:7765237

52. Umbreit NT, Gestaut DR, Tien JF, Vollmar BS, Gonen T, Asbury CL, Davis TN. The Ndc80 kinetochore complex directly modulates microtubule dynamics. Proc Natl Acad Sci U S A. 2012; 109:16113-18. https://doi.org/10.1073/ pnas.1209615109. PMID:22908300

53. Meraldi P, Draviam VM, Sorger PK. Timing and checkpoints in the regulation of mitotic progression. Dev Cell. 2004; 7:45-60. https://doi.org/10.1016/j. devcel.2004.06.006. PMID:15239953

54. Salimian KJ, Ballister ER, Smoak EM, Wood S, Panchenko T, Lampson MA, Black BE. Feedback control in sensing chromosome biorientation by the Aurora B kinase. Curr Biol. 2011; 21:1158-65. https://doi.org/10.1016/j. cub.2011.06.015. PMID:21723127

55. Kapoor TM, Compton DA. Searching for the middle ground: mechanisms of chromosome alignment during mitosis. J Cell Biol. 2002; 157:551-56. https://doi. org/10.1083/jcb.200202073. PMID: 12011106

56. Zaytsev AV, Sundin LJ, DeLuca KF, Grishchuk EL, DeLuca JG. Accurate phosphoregulation of kinetochore-microtubule affinity requires unconstrained molecular interactions. J Cell Biol. 2014; 206:45-59. https://doi.org/10.1083/ jcb.201312107. PMID:24982430

57. Kanda T, Sullivan KF, Wahl GM. Histone-GFP fusion protein enables sensitive analysis of chromosome dynamics in living mammalian cells. Curr Biol. 1998; 8:377-85. https://doi.org/10.1016/s0960-9822(98)701563. PMID:9545195

58. Lundblad JR, Laurance M, Goodman RH. Fluorescence polarization analysis of protein-DNA and protein-protein interactions. Mol Endocrinol. 1996; 10:607-12. https://doi. org/10.1210/mend.10.6.8776720. PMID:8776720

59. Swillens S. Interpretation of binding curves obtained with high receptor concentrations: practical aid for computer analysis. Mol Pharmacol. 1995; 47:1197-203. PMID:7603460

60. Salmela AL, Pouwels J, Varis A, Kukkonen AM, Toivonen P, Halonen PK, Perälä M, Kallioniemi O, Gorbsky GJ, Kallio MJ. Dietary flavonoid fisetin induces a forced exit from mitosis by targeting the mitotic spindle checkpoint. Carcinogenesis. 2009; 30:1032-40. https://doi.org/10.1093/ carcin/bgp101. PMID:19395653

61. Tien JF, Umbreit NT, Gestaut DR, Franck AD, Cooper J, Wordeman L, Gonen T, Asbury CL, Davis TN. Cooperation of the Dam1 and Ndc80 kinetochore complexes enhances microtubule coupling and is regulated by aurora B. J Cell Biol. 2010; 189:713-23. https://doi.org/10.1083/ jcb.200910142. PMID:20479468

62. Gestaut DR, Cooper J, Asbury CL, Davis TN, Wordeman L. Reconstitution and functional analysis of kinetochore 
subcomplexes. Methods Cell Biol. 2010; 95:641-56. https:// doi.org/10.1016/S0091-679X(10)95032-2. PMID:20466157

63. Powers AF, Franck AD, Gestaut DR, Cooper J, Gracyzk B, Wei RR, Wordeman L, Davis TN, Asbury CL. The Ndc80 kinetochore complex forms load-bearing attachments to dynamic microtubule tips via biased diffusion. Cell. 2009; 136:865-75. https://doi.org/10.1016/j.cell.2008.12.045. PMID:19269365

64. Rice S, Lin AW, Safer D, Hart CL, Naber N, Carragher BO, Cain SM, Pechatnikova E, Wilson-Kubalek EM, Whittaker M, Pate E, Cooke R, Taylor EW, et al. A structural change in the kinesin motor protein that drives motility. Nature. 1999; 402:778-84. https://doi.org/10.1038/45483. PMID:10617199
65. Härmä V, Schukov HP, Happonen A, Ahonen I, Virtanen J, Siitari H, Åkerfelt M, Lötjönen J, Nees M. Quantification of dynamic morphological drug responses in 3D organotypic cell cultures by automated image analysis. PLoS One. 2014; 9:e96426. https://doi.org/10.1371/journal.pone.0096426. PMID:24810913 